\section{CONTINUING MEDICAL EDUCATION INFORMATION}

Race Against the Clock: Overcoming Challenges in the Management of Anticoagulant-Associated Intracerebral Hemorrhage

Release Date: August 1, 2014

Last Review: October 25, 2013

Expiration Date: July 31, 2015

Estimated Time to Complete this CME Activity: 1.5 hours

Media/Method of Participation: Journal Article, Web-based posttest, and evaluation

Hardware/Software Requirements: Any Web browser

\section{TARGET AUDIENCE}

This activity has been designed to meet the educational needs of neurosurgeons, residents, fellows, neurosurgical nurses, and physician assistants interested in the practice and business of neurosurgery.

\section{STATEMENT OF NEED}

Neurosurgeons are intimately involved in the emergency management of anticoagulant-treated patients who present with an intracerebral hemorrhage requiring urgent correction of their coagulopathy to prevent worsening hemorrhage and to facilitate surgical intervention as necessary. A number of therapies have been used alone or in combination for the treatment of anticoagulant-associated intracerebral hemorrhage (AAICH) to reverse anticoagulation in order to achieve hemodynamic stability, limit hematoma expansion, and prepare the patient for potential neurologic surgery. Given the essential role of the neurosurgeon, in consult with the emergency department physician, in managing these patients, this enduring activity will elucidate warfarin reversal strategies (and related current controversies) with available and soon-to-be-available therapies for the management of $\mathrm{AAICH}$, and the importance of timely intervention in order to achieve successful reversal of warfarin-induced coagulopathy.

\section{EDUCATIONAL OBJECTIVES}

Upon proper completion of this enduring material, participants should be better able to:

- Appropriately apply evidence-based guidelines and strategies to the management of patients with warfarin-associated ICH.

- Recognize the barriers to successful management of patients with $\mathrm{ICH}$ in the context of anticoagulation-associated coagulopathy.

- Based on risk/benefit analysis of reversal agents, select appropriate therapies for the treatment of patients with $\mathrm{AAICH}$.

\section{FACULTY}

Peter Le Roux, MD, FACS

Professor of Neurosurgery

Thomas Jefferson University Philadelphia, PA

Co-Director, Brain and Spine Center

Lankenau Medical Center

Wynnewood, PA

\author{
Charles V. Pollack, Jr, MA, MD, FACEP \\ Professor \\ Department of Emergency Medicine \\ Perelman School of Medicine \\ University of Pennsylvania \\ Chairman, Department of Emergency Medicine \\ Pennsylvania Hospital \\ Philadelphia, PA
}

\section{SCIENTIFIC DIRECTORS:}

\author{
Melissa Milan, MD
}

Alisa Schaefer, PhD

\section{ACCREDITATION STATEMENT}

Paradigm Medical Communications, LLC is accredited by the Accreditation Council for Continuing Medical Education to provide continuing medical education for physicians.

\section{CREDIT DESIGNATION STATEMENT}

Paradigm Medical Communications, LLC designates this enduring material for a maximum of 1.5 AMA PRA Category 1 Credits $^{\mathrm{TM}}$. Physicians should claim only the credit commensurate with the extent of their participation in the activity.

The American Association of Neurological Surgeons accepts these AMA PRA Category 1 Credits $^{\mathrm{TM}}$ toward the Continuing Education Award in Neurosurgery to maintain membership in the AANS and toward the ABNS Maintenance of Certification program.

\section{INSTRUCTIONS FOR OBTAINING CREDIT}

To receive a CME certificate of participation, participants must:

- Read the entire publication, including the Continuing Medical Education information.

- Register or log in at www.paradigmmc.com/JNSpub to complete and submit the online posttest and evaluation OR complete the posttest/ evaluation form at the end of the article and mail or fax it to Paradigm Medical Communications, LLC, 523 Route 303, Orangeburg, NY 10962; fax (845) 398-5108.

- Answer $70 \%$ of the posttest questions correctly to earn credit. Online completion of the posttest allows unlimited opportunities to successfully complete the posttest.

Following online completion of the posttest and evaluation, a certificate of participation will be available for download/printing immediately. Participants who submit a posttest/evaluation form via mail or fax will receive an email with a link to their certificate of participation within 1 to 2 weeks following receipt of completed form.

For additional questions regarding CME credit, please contact the CME Department of Paradigm Medical Communications, LLC, at (845) 3985949.

\section{DISCLOSURE OF COMMERCIAL SUPPORT}

This CME activity is supported by an educational grant from CSL Behring. 


\section{DISCLOSURES}

In accordance with Accreditation Council for Continuing Medical Education requirements on disclosure, faculty and contributors are asked to disclose any relationships with commercial interests associated with the area of medicine featured in the activity. These relationships are described below.

\section{Peter Le Roux, MD, FACS}

Retained Consultant: Integra LifeSciences; Codman \& Shurtleff, Inc.; Synthes, Inc.

Speakers Bureau: Integra LifeSciences

Contracted Research: Integra LifeSciences

\section{Charles V. Pollack, Jr, MA, MD, FACEP}

Consultant: Astra-Zeneca; Boehringer Ingelheim Pharmaceuticals, Inc; Bristol-Myers Squibb; Daiichi Sankyo, Inc; Janssen Pharmaceuticals, Inc; Pfizer Inc; Sanofi-Aventis U.S. LLC.

Scientific Directors, Melissa Milan, MD, and Alisa Schaefer, PhD have no financial conflicts to disclose.

Paradigm Medical Communications, LLC staff members have no financial conflicts to disclose

\section{Sean D. Lavine, MD—Independent Peer Reviewer}

Director, Endovascular Neurosurgery

Columbia Presbyterian Medical Center

New York, NY

Secretary, AANS/CNS Executive Council of Cerebrovascular Surgery No financial conflicts to disclose.

Jack E. Ansell, MD—Independent Peer Reviewer

Professor of Medicine

Hofstra North Shore/LIJ

School of Medicine

New York, NY

Advisory Board: Boehringer Ingelheim Pharmaceuticals, Inc; BristolMyers Squibb; Daiichi Sankyo, Inc; Janssen Pharmaceuticals, Inc; Perosphere Inc; Pfizer Inc

Shareholder: Perosphere Inc

\section{RESOLUTION OF CONFLICTS OF INTEREST}

Paradigm Medical Communications, LLC has implemented a system to resolve conflicts of interest for each continuing medical education activity to help ensure content objectivity, independence, fair balance, and that the content is aligned with the interest of the public. Conflicts, if any, are resolved through one or more processes. All CME content in this activity was independently reviewed to ensure that it is free of commercial bias, scientifically rigorous, aligned with the public interest, and compliant with all regulatory guidance and the ACCME's Standards for Commercial Support of Continuing Medical Education.

\section{DISCLAIMER}

This CME activity represents the views and opinions of the individual faculty, and does not constitute the opinion or endorsement of, or promotion by, Paradigm Medical Communications, LLC. Reasonable efforts have been taken to present educational subject matter in a balanced, unbiased fashion, and in compliance with regulatory requirements. However, each activity participant must always use his or her own personal and professional judgment when considering further application of this information, particularly as it may relate to patient diagnostic or treatment decisions including, without limitation, FDA-approved uses and any off-label uses.

\section{TERMS OF USE AND PRIVACY POLICY}

\section{Disclaimer}

The information presented in this activity is for informational purposes only, and should not be used for diagnosis or treatment of a health problem without consulting a licensed medical professional. Any views or opinions presented in this article are solely those of the Faculty, and do not necessarily represent those of Paradigm Medical Communications, LLC. References to any entity, product, service, or source of information in this article should not be considered an endorsement, either direct or implied, by Paradigm Medical Communications, LLC. Paradigm Medical Communications, LLC accepts no liability for the content referenced in this activity.

\section{Privacy policy}

Paradigm Medical Communications, LLC is committed to protecting the privacy of those who participate in the activities (herein referred to as "website") located at www.paradigmmc.com. The paragraphs below describe the security of the website for safeguarding personal information and the rationale for collection and use of personal information.

\section{Security/safeguarding personal information}

This website has physical and procedural safeguards in place to prevent unauthorized access to personal information used to access this website.

\section{Collection and use of your personal information}

To earn CME credits using the website, the submission of certain personally identifiable information is necessary. The required items include: first name, last name, degree, and e-mail address. These items are necessary to award and track the credits participants may earn after completing the program. Participants are required to complete an evaluation of the CME activity. All evaluative information submitted is collected and retained, and assists the staff of Paradigm Medical Communications, LLC in continuously improving the learning experience.

Paradigm Medical Communications, LLC does not transfer, sell, or share personal information with outside parties. Paradigm Medical Communications, LLC will not otherwise disclose personal information unless required to in a legal process. Paradigm Medical Communications, LLC staff members review individual test results to the extent necessary to record and track participant credits.

\section{CONTACT US}

If you have any questions or comments regarding this policy, please send e-mail to contactus@paradigmmc.com.

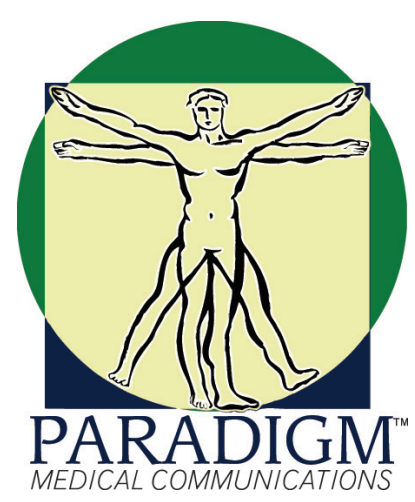




\title{
Race against the clock: Overcoming challenges in the management of anticoagulant-associated intracerebral hemorrhage
}

\author{
Peter Le Roux, M.D., ${ }^{1}$ Charles V. Pollack JR., M.A., M.D., ${ }^{2}$ \\ Melissa Milan, M.D., ${ }^{3,4}$ and Alisa Schaefer, Ph.D. ${ }^{3}$
}

${ }^{1}$ Thomas Jefferson University, Philadelphia, Pennsylvania and Brain and Spine Center, Lankenau Medical Center, Wynnewood, Pennsylvania; ${ }^{2}$ Department of Emergency Medicine, Perelman School of Medicine, University of Pennsylvania and Department of Emergency Medicine, Pennsylvania Hospital, Philadelphia, Pennsylvania; ${ }^{3}$ Paradigm Medical Communications, LLC, Orangeburg, New York; and ${ }^{4}$ Union Memorial Hospital, Baltimore, Maryland

Patients receiving anticoagulation therapy who present with any type of intracranial hemorrhage - including subdural hematoma, epidural hematoma, subarachnoid hemorrhage, and intracerebral hemorrhage (ICH) - require urgent correction of their coagulopathy to prevent hemorrhage expansion, limit tissue damage, and facilitate surgical intervention as necessary. The focus of this review is acute ICH, but the principles of management for anticoagulation-associated ICH (AAICH) apply to patients with all types of intracranial hemorrhage, whether acute or chronic.

A number of therapies - including fresh frozen plasma (FFP), intravenous vitamin K, activated and inactivated prothrombin complex concentrates (PCCs), and recombinant activated factor VII (rFVIIa) - have been used alone or in combination to treat AAICH to reverse anticoagulation, help achieve hemodynamic stability, limit hematoma expansion, and prepare the patient for possible surgical intervention. However, there is a paucity of high-quality data to direct such therapy. The use of 3 -factor PCC (activated and inactivated) and rFVIIa to treat AAICH constitutes off-label use of these therapies in the United States. However, in April 2013, the US Food and Drug Administration (FDA) approved Kcentra (a 4-factor PCC) for the urgent reversal of vitamin K antagonist (VKA) anticoagulation in adults with acute major bleeding. Plasma is the only other product approved for this use in the United States. ${ }^{1}$ Inconsistent recommendations, significant barriers (e.g., clinician-, therapy-, or logistics-based barriers), and a lack of approved treatment pathways in some institutions can be potential impediments to timely and evidence-based management of AAICH with available therapies. Patient assessment, therapy selection, whether to use a reversal or factor repletion agent alone or in combination with other agents, determination of site-of-care management, eligibility for neurosurgery, and potential hematoma evacuation are the responsibilities of the neurosurgeon, but ultimate success requires a multidisciplinary approach with consultation from the emergency department (ED) physician, pharmacist, hematologist, intensivist, neurologist, and, in some cases, the trauma surgeon.

(http://thejns.org/doi/abs/10.3171/2014.8.paradigm)

Abbreviations: $\mathrm{AAICH}=$ anticoagulation-associated intracerebral hemorrhage; $\mathrm{AF}=$ atrial fibrillation; $\mathrm{AHA}=\mathrm{American}$ Heart $\mathrm{Association}$; aPTT = activated partial thromboblastin time; ASA = American Stroke Association; $\mathrm{BP}=$ blood pressure; $\mathrm{bpm}=$ beats per minute; $\mathrm{BT}=\mathrm{bleeding}$ time; $\mathrm{CI}=$ confidence index; $\mathrm{CT}=$ computed tomography; $\mathrm{CYP}=$ cytochrome P450; DVT = deep vein thrombosis; ECT = ecarin clotting time; $\mathrm{ED}=$ emergency department 4PCC = four-factor prothrombin complex concentrate; FFP = fresh frozen plasma; GCS = Glasgow Coma Scale; $\mathrm{HR}=$ heart rate; ICES = intraoperative computed tomography-guided endoscopic surgery procedure; ICH = intracerebral hemorrhage; INR = international normalized ratio; IV = intravenous; IVH = intraventricular hemmorhage; MISTIE = Minimally Invasive Surgery plus recombinant Tissue plasminogen activator for ICH Evaluation procedure; NOAC $=$ novel oral anticoagulant; OAC $=$ oral anticoagulant; $\mathrm{PCC}=$ prothrombin complex concentrate; $\mathrm{PE}=$ pulmonary embolism; $\mathrm{PHE}=$ perihematomal edema; $\mathrm{PT}=$ prothrombin time; $\mathrm{PTT}=$ partial thromboplastin time; $\mathrm{rFVIIa}=$ recombinant factor VII; RR = respiratory rate; rt-PA = recombinant tissue plasminogen activator; $3 \mathrm{PCC}=$ three-factor prothrombin complex concentrate; $\mathrm{TT}=$ thrombin time; $\mathrm{VKA}=$ vitamin $\mathrm{K}$ antigen. 
ntracerebral hemorrhage $(\mathrm{ICH})$ is a potentially devastating type of stroke with an estimated incidence between $0.012 \%$ and $0.26 \% .^{2-5}$ Mortality at 1 month following $\mathrm{ICH}$ is about $40 \%$, and only $12 \%$ to $39 \%$ of patients are able to function independently at 12 months. ${ }^{5}$ Use of anticoagulant therapy increases the risk of developing ICH by 7 - to 10 -fold, and anticoagulation-associated ICH (AAICH) accounts for up to $19 \%$ of all ICH cases. ${ }^{6,7}$ The mortality rate due to $\mathrm{AAICH}$ is high despite anticoagulant reversal and factor repletion therapy; it is as high as $42.3 \%$ to $67 \%$ even following prothrombin complex concentrate (PCC) therapy. ${ }^{7-9}$ The high mortality rates may be driven, at least in part, by hemorrhage expansion, as AAICH is associated with greater expansion than spontaneous $\mathrm{ICH} .{ }^{8}$ Importantly, mortality due to $\mathrm{AAICH}$ has not improved over the last 20 years, ${ }^{10}$ indicating that there are barriers to AAICH treatment and room for improvement.

The use of anticoagulation therapy is increasing, as the aging population grows and the prevalence of conditions such as atrial fibrillation that require long-term anticoagulation treatment rises. ${ }^{6}$ In 2004, there were 31 million outpatient prescriptions for warfarin in the United States, a $45 \%$ increase over a 6 -year period. ${ }^{6}$ The approval of the targeted oral anticoagulant (OAC) therapies dabigatran etexilate, rivaroxaban, and apixaban portends both a wider use of oral anticoagulation and a growing clinical concern about best practices in AAICH management.11

Both thrombotic events due to discontinuing anticoagulation therapy and bleeding complications due to not reversing anticoagulation increase morbidity and mortality in AAICH patients. Thus, an individualized approach is necessary and should be based on the individual patient's medical history, pathophysiology, risk for thrombosis, and risk of bleeding, as well as the specific OAC being used. For example, a patient with a mechanical mitral valve who has an AAICH should be put back on anticoagulation therapy as soon as clinically possible; a patient 5 months into a 6 -month course of rivaroxaban for deep venous thrombosis (DVT) might not require reinitiation of anticoagulation after $\mathrm{AAICH}$ treatment. Monitoring the patient, considering the need for continued anticoagulation and overall bleeding risk, adjusting the dosage of medication, and ensuring the patient adheres to the dosing regimen are key elements

\section{Learning Objectives}

- Appropriately apply evidence-based guidelines and strategies to the management of patients with warfarin-associated ICH.

- Recognize the barriers to successful management of patients with ICH in the context of anticoagulation-associated coagulopathy.

- Based on risk/benefit analysis of reversal agents, select appropriate therapies for the treatment of patients with AAICH.

to ensure patient safety. ${ }^{12}$ This review aims to provide a foundation to help clinicians understand the OACs and current strategies in anticoagulation reversal.

\section{Oral Anticoagulation Therapies}

\section{Warfarin}

The most widely used oral anticoagulant, ${ }^{13}$ warfarin is a racemic mixture of enantiomers of a VKA, with the $S$ enantiomer the more biologically active component of the racemic mixture. Warfarin inhibits vitamin $\mathrm{K}$ epoxide reductase (VKORC1), the enzyme required for the synthesis in the liver of coagulation factors II, VII, $\mathrm{IX}$, and $\mathrm{X}$, and proteins $\mathrm{C}$ and $\mathrm{S} .{ }^{13}$ These factors are biologically inactive in the absence of vitamin $\mathrm{K}$, and therefore warfarin use results in the synthesis of coagulation factors II, VII, IX, and X with reduced coagulation activity (Figure $1^{14}$ ). Upon oral administration, warfarin is rapidly absorbed from the gastrointestinal tract and reaches its maximal blood concentration at 90 minutes. Warfarin accumulates in the liver, where it is metabolized primarily by cytochrome P450 (CYP) 2C9 (the $S$ enantiomer) and CYP1A2 and CYP3A4 (the $R$ enantiomer), resulting in a half-life of 36 to 42 hours. ${ }^{13}$

Warfarin has a narrow therapeutic index, which is maintained by adjusting the dose to an international normalized ratio (INR) of 2.0 to 3.0 for most condi- 


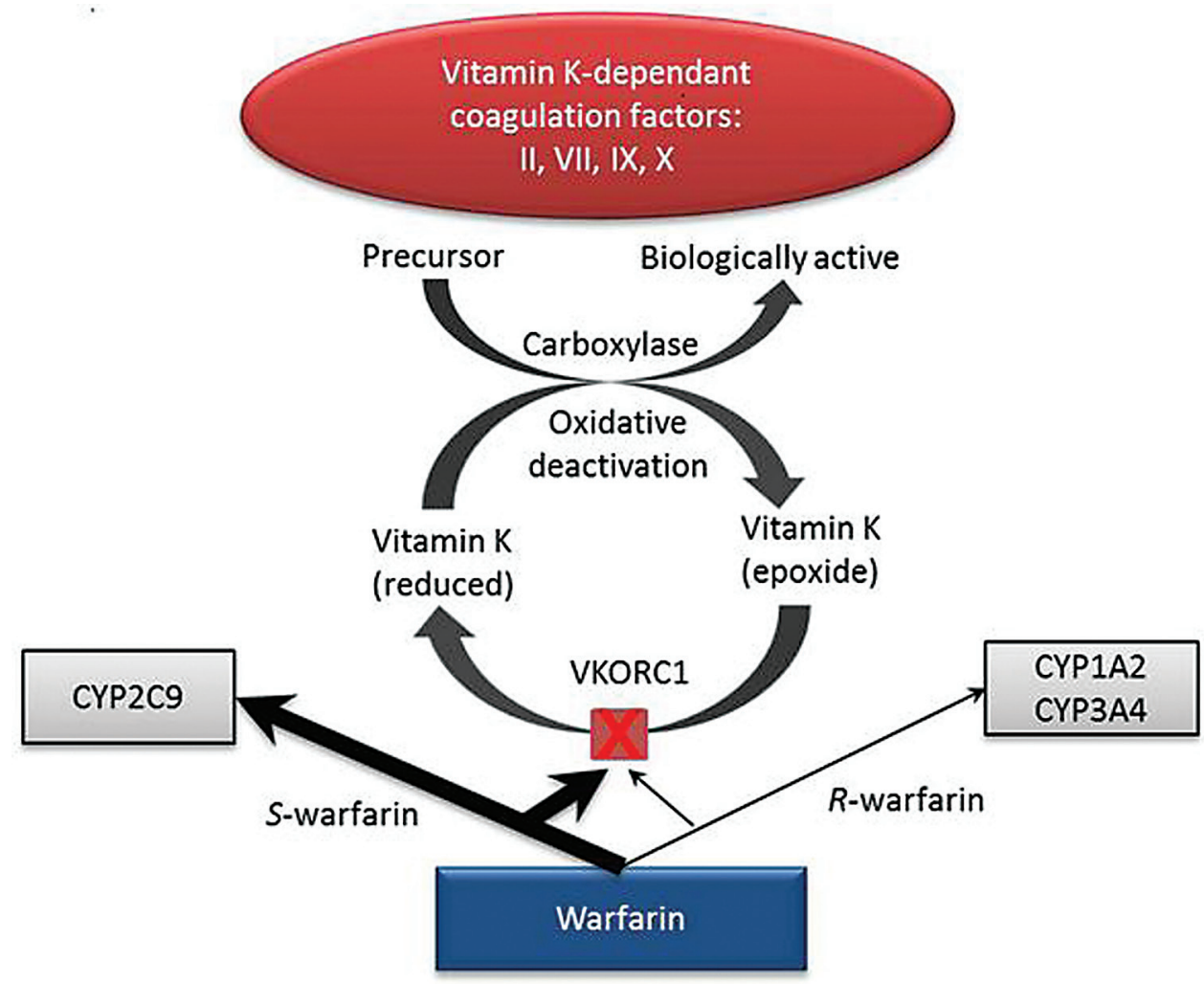

Figure 1: Mechanisms of Action of Warfarin ${ }^{14}$

Warfarin acts by inhibiting the synthesis of vitamin K-dependent clotting factors, which include factors II, VII, IX, and X, and the anticoagulant proteins C and S. Copyright 2009-2013 Baishideng Publishing Group Co., Limited. All rights reserved.

tions. ${ }^{15}$ However, warfarin is known to have multiple food-drug and drug-drug interactions, as well as a vulnerability to genetic polymorphisms, all of which can affect the efficacy and consistency of the anticoagulation effect (as measured by INR) and lead to serious adverse events. ${ }^{16-20}$

\section{Targeted Oral Anticoagulants}

Given these limitations of warfarin, there has long been interest in developing OACs that do not require monitoring, have a wider therapeutic index, and have a cleaner pharmacologic profile (Figure $2^{21-24}$ ). Various targeted OACs have been approved in recent years for the prevention of stroke and systemic emboli in patients with nonvalvular AF and for the prevention and treatment of venous thromboembolism. These drugs include the direct thrombin inhibitor dabigatran (Pradaxa ${ }^{\circledR}$, Boehringer Ingelheim, Ingelheim am
Rhein, Germany) ${ }^{21}$ and the direct factor Xa inhibitors rivaroxaban (Xarelto ${ }^{\circledR}$, Janssen Pharmaceuticals, Inc., Titusville, NJ, USA), ${ }^{22}$ apixaban (Eliquis ${ }^{\circledR}$, BristolMyers Squibb, New York, NY, USA), ${ }^{23}$ and edoxaban (Lixiana®, Daiichi Sankyo, Tokyo, Japan). An overview of the characteristics and pharmacology of the various targeted OACs is given in Table 1.21,24-26

Direct thrombin inhibitors. Dabigatran etexilate is approved for use in the US to reduce the risk of stroke and systemic embolism in patients with nonvalvular atrial fibrillation (AF), for the treatment of DVT and PE in patients who have been treated with a parenteral anticoagulant for 5-10 days, and to reduce the risk of recurrence of DVT and PE in patients who have been previously treated. Dabigatran directly and reversibly binds to the active site of thrombin and inactivated fibrin-bound thrombin, thereby inhibiting its interaction with its substrates. ${ }^{27}$ Upon oral administration, dabi- 
Le Roux et al.

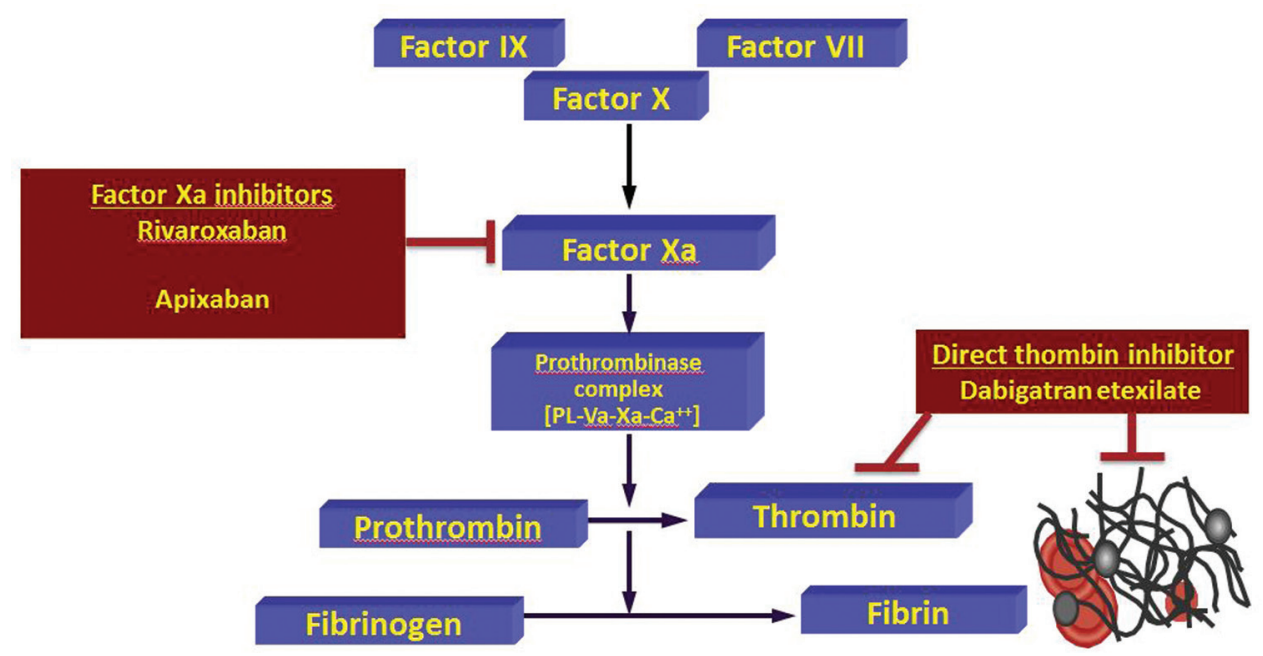

Figure 2: Novel oral anticoagulant (NOAC) Mechanism of Action ${ }^{21-24}$

The factor $\mathrm{Xa}$ inhibitors, rivaroxaban and apixaban, and the direct thrombin inhibitor, dabigatran etexilate, have different mechanisms of action. The factor Xa inhibitors serve as competitive reversible antagonists of Xa, which is the active component of the prothrombinase complex that catalyzes the conversion of prothrombin (factor II) to thrombin (factor Ila). The direct thrombin inhibitor, dabigatran etexilate, is a competitive reversible antagonist of thrombin, which converts fibrinogen to fibrin.

gatran etexilate is converted to its active metabolite, dabigatran, ${ }^{28,29}$ and reaches its maximum therapeutic concentration within 1 to 3 hours. Dabigatran etexilate requires an acidic environment for absorption; however, its absorption is not affected by gastric $\mathrm{pH}$ due to the drug's formulation. ${ }^{28}$ Continuous dosing of dabigatran etexilate results in a half-life of 12 to 17 hours, with $80 \%$ of unchanged dabigatran etexilate excreted in the urine and the remaining excreted primarily through bile. ${ }^{28}$ Patients with significant renal insufficiency should be prescribed a reduced dose or an alternative OAC should be considered. ${ }^{30}$

Unlike VKAs, prothrombin time (PT/INR) is not sensitive to dabigatran's activity, and patients with considerable dabigatran levels can have normal or near-normal PT/INR. ${ }^{31}$ Activated partial thromboplastin time (aPTT) can be used qualitatively to confirm the presence of dabigatran if current use is uncertain, but it is relatively insensitive to the effects of direct thrombin inhibitors and cannot be used to assess anticoagulation intensity. ${ }^{28}$ The thrombin time (TT) and ecarin clotting time (ECT) provide more accurate measures of dabigatran activity, although the TT tends to be oversensitive and the ECT is neither standardized nor readily available in the United States. ${ }^{28}$

Direct factor $\mathrm{Xa}$ inhibitors. Factor $\mathrm{Xa}$ binds to activated factor $V$ that is present on activated platelets, forming the prothrombinase complex, which is important in the conversion of prothrombin to thrombin. Direct factor Xa inhibitors, such as rivaroxaban, apixaban, and edoxaban, reversibly bind to the active site of activated factor Xa to ultimately inhibit thrombin formation. ${ }^{28}$

Rivaroxaban is approved by the FDA to reduce the risk of stroke and systemic embolism in patients with nonvalvular AF; for the treatment of DVT and pulmonary embolism (PE) as well as for the reduction in the risk of recurrence of DVT and PE; and for the prophylaxis of DVT, which may lead to PE in patients undergoing knee or hip replacement surgery. ${ }^{22}$ Rivaroxaban has $80 \%$ to $100 \%$ bioavailability at the $10-\mathrm{mg}$ dose and $66 \%$ bioavailability at the 20 -mg dose, and it reaches its maximum therapeutic concentration within 2 to 4 hours. ${ }^{28}$ Most of rivaroxaban is metabolized in the liver by CYP3A4, CYP2Cl, and CYP-independent enzymes, 
Table 1: NOACs: Overview and Pharmacology21,24-26

\begin{tabular}{|l|l|l|l|}
\hline & \multicolumn{1}{|c|}{ Apixaban ${ }^{21,24}$} & \multicolumn{1}{c|}{ Dabigatran ${ }^{21,25}$} & \multicolumn{1}{c|}{ Rivaroxaban ${ }^{21,26}$} \\
\hline Drug class & Direct factor Xa inhibitor & Direct factor Ila inhibitor & Direct factor Xa inhibitor \\
\hline Bioavailability & $50 \%$ & $3 \%-7 \%$ & $\begin{array}{l}80 \%-100 \% \text { for } 10-\mathrm{mg} \text { dose } \\
66 \% \text { for } 20-\mathrm{mg} \text { dose }\end{array}$ \\
\hline Tmax & $1-4 \mathrm{hr}$ & $1-3 \mathrm{hr}$ & $2-4 \mathrm{hr}$ \\
\hline CYP metabolism & $15 \%-25 \%$ CYP3A4 & No & $30 \%$ CYP3A4, CYP2J2 \\
\hline Renal excretion & $25 \%$ & $80 \%$ & $36 \%$ \\
\hline Half-life & $8-15 \mathrm{hr}$ & $12-17 \mathrm{hr}$ & $5-9 \mathrm{hr}$ \\
\hline Dosage form & Tablet & Capsule & Tablet \\
\hline Dosing frequency & BID & BID & Once daily \\
\hline
\end{tabular}

Apixaban, dabigatran and rivaroxaban have a rapid onset and short half-life.

Abbreviations: $\mathrm{BID}=2$ times per day; $\mathrm{CYP}=$ cytochrome $\mathrm{p} 450 ;$ Tmax = time to maximum concentration.

and $66 \%$ of rivaroxaban is excreted through the urine ( $50 \%$ of which is excreted as unchanged drug) with the remainder excreted unchanged in the feces. ${ }^{28}$ The half-life of rivaroxaban is 5 to 9 hours in young, healthy patients and increases to 11 to 13 hours in elderly patients due to normal age-associated renal decline. ${ }^{28}$ The PT can be used qualitatively to confirm the presence of rivaroxaban, but it cannot be used to assess anticoagulation intensity quantitatively and its sensitivity to rivaroxaban is very reagent dependent. ${ }^{31}$ A chromogenic, specific anti-Xa assay is available to quantitatively measure rivaroxaban, but it is not readily available at most hospitals, nor is it a rapid turnaround assay.

Apixaban is approved by the FDA for the reduction of risk of stroke and systemic embolism in nonvalvular AF, and for the prophylaxis of DVT following hip

Table 2: Comparison of pharmacologic properties of NOACs vs. warfarin ${ }^{25,27}$

\begin{tabular}{|c|c|c|}
\hline Characteristic & NOACs & Warfarin \\
\hline Onset/offset of action & Rapid/shorter (effect declines rapidly if poor adherence $=\downarrow$ efficacy) & Slow/long \\
\hline Dosing & Fixed & Variable \\
\hline Dietary interactions & No & Yes \\
\hline Drug interactions & Few & Many \\
\hline \multicolumn{3}{|c|}{ Disadvantages } \\
\hline Frequency & Once or twice daily* & Once daily \\
\hline Clearance & Renal $25 \%-80 \%$ & Nonrenal \\
\hline Antidote & None & Vitamin K, FFP, PCC \\
\hline
\end{tabular}

*Dabigatran and apixaban. 
or knee replacement surgery. ${ }^{23}$ Apixaban is rapidly absorbed following oral administration, with a bioavailability of $66 \%$, and reaches its maximum therapeutic concentration within 1 to 4 hours. ${ }^{28}$ Apixaban is metabolized by CYP3A4; $25 \%$ is excreted through urine and about $55 \%$ is excreted through the feces, resulting in a half-life of 8 to 15 hours in young, healthy patients. ${ }^{28}$ Despite being a substrate for CYP3A4, apixaban is not likely to have significant drug-drug interactions. ${ }^{28} \mathrm{~A}$ modified PTT assay can be used to qualitatively assess apixaban anticoagulation. ${ }^{31}$ Similar to rivaroxaban, a specific anti-Xa assay can measure apixaban levels quantitatively.

Although warfarin is the most widely used anticoagulant in the world, the approval of the targeted OACs has expanded the available treatment options, particularly in the prevention of stroke in nonvalvular AF. Warfarin has been demonstrated to be effective yet has limitations that are described above. The targeted OACs have predictable pharmacokinetics and do not require regular laboratory monitoring; they have minimal fooddrug and drug-drug interactions, a wide therapeutic index, and rapid onset and offset (Table 25,27). ${ }^{30}$ However, one of the cited advantages of the targeted OACs - the absence of a need for routine monitoring is also a challenge, particularly in conditions that may warrant rapid anticoagulation reversal; the ability to measure the extent of anticoagulation is also helpful. ${ }^{29}$ In addition, there is extensive clinical experience in the use of warfarin, whereas there is limited experience with targeted OACs.

\section{Management of Anticoagulant- Associated Bleeding}

The annual incidence of any warfarin-associated major bleed is $0 \%$ to $16 \%$, and the annual incidence of a warfarin-associated fatal bleed is $0 \%$ to $2.9 \% .{ }^{26}$ Although dabigatran and rivaroxaban do not significantly decrease the risk of overall bleeding events compared with warfarin, the targeted OACs have a lower risk of $\mathrm{AAICH} .{ }^{32,33}$ Treatment with apixaban appears generally to decrease the risk of bleeding, including major and serious bleeds, as well as ICH, compared to warfarin. ${ }^{34}$ According to the RE-LY, ROCKET-AF, and ARISTOTLE trials, the risk of developing $\mathrm{AAICH}$ is reduced by $60 \%$ to $69 \%$ with dabigatran etexilate, $33 \%$ with rivaroxaban, and $58 \%$ with apixaban, when compared to warfarin. ${ }^{32-34}$ Targeted OACs affect a single factor in the coagulation cascade, whereas warfarin affects multiple factors, including factor VII, which when activated by tissue factor is the primary initiator of the coagulation cascade. The brain is rich in tissue factor. Warfarin interrupts the interaction between tissue factor and factor VII, while the targeted OACs do not. This might provide at least a partial explanation for the reduction in $\mathrm{AAICH}$ seen in clinical trials of the targeted OACs compared with warfarin..$^{35}$ In contrast to VKA reversal, not only are there no specific antidotes for the targeted OACs, there are also currently no evidencebased reversal strategies. ${ }^{35}$

The focus of AAICH treatment is prevention of hematoma expansion, which is primarily achieved through anticoagulation reversal and/or factor repletion, as hematoma expansion is associated with neurologic deterioration and poor long-term outcomes. The risk of expansion of a spontaneous $\mathrm{ICH}$ is estimated to be $20 \%$ to $40 \%$. ${ }^{16,36,37}$ Interestingly, most warfarin-associated ICHs occur in the conventional INR range of 2.0 to $3.5,{ }^{16}$ although the risk of such an event is presumably higher when the INR is elevated.

\section{Warfarin Reversal}

Presentation of $\mathrm{AAICH}$ requires an immediate response, as one of the most important factors in patient prognosis is time to treatment. ${ }^{38}$ The VKA should be discontinued and reversal of anticoagulation and repletion of deficient factors should occur immediately with the goal of preventing hematoma expansion. Patients who present with VKA-associated ICH should first receive $2.5 \mathrm{mg}$ to $10 \mathrm{mg}$ of intravenous (IV) vitamin $\mathrm{K} 1$ over a 30 -minute period. This allows the liver, which may be depleted of vitamin $\mathrm{K} 1$ and its associated coagulation factors, to synthesize vitamin K-dependent coagulation factors. This synthesis can take up to 24 hours; therefore, vitamin $\mathrm{K} 1$ should be administered with either fresh frozen plasma (FFP) or PCCs to more quickly replete coagulation factors. ${ }^{11,38}$ For FFP, 15 to $30 \mathrm{ml} /$ $\mathrm{kg}$ should be infused over 3 to 6 hours, whereas PCC is administered at 25 to $100 \mathrm{UI} / \mathrm{kg}$ over 10 minutes to 1 hour. ${ }^{11}$ 
Fresh frozen plasma. Although FFP rapidly restores coagulation factors, ${ }^{11}$ there are disadvantages to its use. It requires thawing for approximately 30 minutes at between $30^{\circ} \mathrm{C}$ and $37^{\circ} \mathrm{C}$, as well as patient blood typing. ${ }^{39}$ In addition, large volumes of FFP are required, ${ }^{38}$ which subjects patients to risk of volume overload ${ }^{40}$ and can cause pulmonary microvascular damage, potentially requiring ventilation and leading to death. ${ }^{39}$ For example, an average adult patient weighing $70 \mathrm{~kg}$ will receive about $1050 \mathrm{ml}$ of FFP. ${ }^{40}$ Patients at risk of volume overload typically require a slower infusion rate, which prolongs the time to anticoagulation reversal. ${ }^{38}$ Infusion with FFP also carries a small risk for viral or prion transmission, passive alloimmune thrombocytopenia, anaphylactoid reactions, and septicemia. ${ }^{11}$

Prothrombin complex concentrates. PCCs are virally inactivated, vitamin K-dependent coagulation factors prepared from pooled plasma agents that are lyophilized and designed to be dissolved in saline as needed. ${ }^{40}$ Treatment with PCCs is rapid and efficacious, as they replenish key coagulation factors that are depleted in patients who have been treated with warfarin. PCCs also have a relatively safe profile and require a low-volume infusion. The 3-factor PCCs are administered off label in cases of $\mathrm{AAICH}$, as they are indicated for the reversal of bleeding in patients with hemophilia B, at 25 to $100 \mathrm{Ul} / \mathrm{kg}$, and infused over 10 $\min$ to $1 \mathrm{hr}$ to patients on warfarin with an INR $>2$ and evidence of ICH on a computed tomography (CT) scan. PCCs have 2 important advantages over FFP: 1) they can be administered more quickly (thawing and blood typing are not required), with repletion achieved within 15 minutes; and 2) there is no risk of volume overload. However, PCCs are more expensive and carry a low but finite risk of correction thrombosis, ${ }^{40}$ and the content of the cofactors with each dose may vary. ${ }^{11}$

The 2 types of PCC include 3-factor PCC (3PCC), which contains factors II, IX, and X, and 4-factor PCC (4PCC), which contains factors II, IX, X, and VII.. ${ }^{11}$ Three-factor PCCs have been approved in the United States to prevent and control bleeding episodes in adult patients with hemophilia $B$, but are used off label to treat $\mathrm{AAICH}$ under the trade names Bebulin ${ }^{\mathrm{V}} \mathrm{VH}$ (Baxter International, Inc., Amsterdam, Netherlands) and Profilnine ${ }^{\circledR}$ SD (Grifols, Barcelona, Spain). ${ }^{11}$ In a single-center study, 70 patients who required anticoagulation reversal due to warfarin-associated $\mathrm{ICH}$ received a 3PCC and were evaluated for adverse events. ${ }^{41}$ The mean INR decreased from 3.36 to 1.96 in $63 \%$ of patients and concomitant administration of FFP did not affect INR correction. However, $10 \%$ of the patients experienced serious adverse events and 2 patients died from suspected PE. The authors concluded that reversal is incomplete with 3PCCs. ${ }^{41}$

In the United States, the first 4PCC (Kcentra®, CSL Behring, King of Prussia, PA, USA) was approved in April 2013 for the reversal of acquired coagulation factor deficiency induced by vitamin $\mathrm{K}$ antagonist therapy in adult patients, but these PCCs have been used in Europe and Canada for a number of years. Although there is a lack of comparison trials, recent studies suggest that 4PCCs may provide better INR correction than 3PCCs. ${ }^{42}$ In a meta-analysis of 18 studies that included 654 patients, treatment of patients who required urgent reversal because of $\mathrm{AAICH}$, surgery, or invasive procedures with 4PCCs resulted in more reliable INR reduction than 3 PCC therapy. ${ }^{42}$

The use of 4PCCs in urgent VKA reversal appears to result in a greater reduction in INR compared to reversal by plasma or FFP. In a phase 3 open-label study, 59 patients with VKA-associated $\mathrm{ICH}$ were randomized to receive 25 or $40 \mathrm{IU} / \mathrm{kg}$ of $4 \mathrm{PCC} .{ }^{43}$ In both treatment arms, the mean INR was significantly decreased at 10 minutes following the infusion, and the mean INR in the 40-IU/kg arm was significantly lower than the mean INR in the 25-IU/kg arm at 10 minutes $(p=0.001), 1$ hour ( $p$ $=0.001)$, and 3 hours $(p=0.02)$. In addition, there were no differences in adverse events, hematoma volume, or clinical outcomes between the treatment arms. ${ }^{43}$ The data from this trial suggest that a higher dose of 4PCCs can achieve a lower INR. However, further studies are required to determine if this translates into improved clinical outcomes. In an open-label phase $3 b$ trial, 202 patients receiving VKAs who presented with major bleeding were randomized to receive $4 \mathrm{PCC}$ or plasma. ${ }^{44} \mathrm{~A}$ decrease in INR was achieved in $62.2 \%$ of patients who received the 4PCC compared to $9.6 \%$ of patients who received plasma. In addition, coagulation factors were greater in the arm that received the 4PCC beginning at 30 minutes and up to 3 hours following 
infusion initiation $(p<0.02)$. Adverse events and serious adverse events were similar among the treatment arms. ${ }^{44}$ The trial results indicate that the 4PCC is superior to plasma in decreasing INR, with a similar safety profile. In a retrospective study that compared 4PCCs to FFP in patients receiving warfarin with an INR $\geq 1.5$ who required urgent anticoagulation reversal, patients treated with the 4PCC demonstrated a greater INR reduction than patients who received FFP. ${ }^{45}$ In addition, serious adverse events occurred in $9.7 \%$ of patients who received the 4PCC and $19.5 \%$ of patients who received FFP $(p=0.014) .{ }^{45}$

Recombinant Factor VIIa. Another agent that has been used to help manage $\mathrm{ICH}$, including $\mathrm{AAICH}$, is recombinant factor VIla (rFVIla). To help treat $\mathrm{AAICH}$, this agent is administered off label as a 10- to $90-\mu \mathrm{g} /$ $\mathrm{kg}$ bolus injection given over 15 minutes. A concern when using rFVIla is the potential for a rebound INR increase and prothrombosis. In the phase 3 FAST trial, 841 patients with spontaneous ICH (excluding patients treated with OACs) were randomized to receive 20 or $40 \mu \mathrm{g}$ of $\mathrm{rFVlla}$ or placebo within 4 hours of stroke onset. ${ }^{46}$ Although the patients who received 20 or 40 $\mu \mathrm{g}$ of $\mathrm{rFVIla}$ experienced less hematoma expansion compared to placebo ( $p=0.09$ and $p<0.001$, respectively), clinical outcomes and survival were similar in all treatment groups. ${ }^{46}$ The rates of adverse events were similar among the treatment and placebo groups; however, significantly more arterial events occurred in patients who received the higher dose of rFVIla than placebo ( $46 \%$ vs $27 \%$; $p=0.04) .{ }^{47}$ Whether these data can be used to inform treatment of $\mathrm{AAICH}$ is uncertain since the FAST trial was not conducted in patients with AAICH. In a retrospective study of 101 patients with warfarin-associated $\mathrm{ICH}$ treated with $\mathrm{rFVIIa,} \mathrm{the} \mathrm{rate}$ of adverse events was similar to that observed in the FAST trial: 13 patients (12.9\%) developed thromboembolic events within 90 days of rFVIla infusion. ${ }^{48}$

Trials in which rFVIla is compared with other reversal agents in humans are lacking. However, a comparison study of 4PCC versus rFVIla conducted in rats demonstrated that 4PCC therapy had greater efficacy than $\mathrm{rFVIla} .^{49}$ Although both agents almost completely reversed PT/INR, rFVIla decreased PT/INR and the 4PCC resulted in full normalization. In addition, 4PCC treatment resulted in significantly improved aPTT ( $p$ $<0.01)$, blood loss $(p<0.01)$, and bleeding time $(p=$ 0.008), whereas rFVIla had no significant effect. ${ }^{49}$

It is important to note that although the standard of care is to correct INR, with the goal of reversing anticoagulation to limit hemorrhage expansion, the role of INR in the outcomes of patients with AAICH is unclear. There is a lack of randomized, controlled data that indicate that INR normalization reduces hematoma expansion and decreases mortality. ${ }^{50} \mathrm{~A}$ small study of 13 patients randomized to receive FFP or FFP plus PCC failed to demonstrate a significant difference in neurological outcomes, despite a significant improvement in INR in the FFP plus PCC arm. ${ }^{50}$ In addition, in the warfarinassociated ICH (WAICH) study, $80 \%$ of patients had INR normalization to $<1.5$ within 1 hour of treatment with PCC, yet $47 \%$ of the patients still experienced hematoma expansion with an in-hospital mortality rate of $44 \% .{ }^{9}$ Therefore, it appears that INR correction alone is not sufficient to reduce the risk of mortality in many patients.

\section{Targeted Oral Anticoagulant Reversal}

Despite their convenience, efficacy, and lower AAICH risk, a major limitation of the targeted OACs is that there is currently no specific antidote for any of the agents. Furthermore, there are no evidence-based strategies that can be used to guide treatment of targeted OACassociated $\mathrm{ICH}$. Therefore, current strategies that are frequently used include discontinuation of the targeted $\mathrm{OAC}$ and removal of the drug from the systemic circulation, if possible. ${ }^{29}$

Dabigatran etexilate. In addition to discontinuation, treatment of $\mathrm{AAICH}$ associated with dabigatran use may include activated charcoal administration, if the last dose was taken within the previous 2 hours. ${ }^{51}$ Dabigatran is a dialyzable drug, and if necessary, emergency dialysis can be used to reduce the amount of drug in patients with life-threatening bleeding. ${ }^{51,52}$ Theoretically, because dabigatran is a direct thrombin inhibitor, administration of PCC may overcome thrombin inhibition. ${ }^{51}$ However, in a randomized, doubleblind, placebo-controlled study of 12 healthy males, 4PCC administration following 2.5 days of dabigatran 
dosing did not restore PTT, ECT, or TT to normal levels..$^{53}$ In a murine model of dabigatran-associated $\mathrm{ICH}$, treatment with FFP or PCC decreased hematoma expansion, although only PCC was effective at higher doses of dabigatran. ${ }^{54}$ In addition, PCC improved functional outcome. ${ }^{54}$

Rivaroxaban. Since the half-life of rivaroxaban is so short, stopping the drug is an important measure to manage cases of $\mathrm{AAICH}$ associated with its use. Although no studies have evaluated its use, activated charcoal may also be a reasonable therapy in patients who have recently taken rivaroxaban. ${ }^{31}$ However, rivaroxaban is highly plasma protein bound and cannot be dialyzed; therefore, dialysis is not an option. ${ }^{31}$ In a randomized, placebo-controlled study of 12 healthy males who received rivaroxaban for 2.5 days, 4PCC treatment resulted in rapid and complete reversal of PTT compared to baseline $(p<0.001) .^{53}$ Therefore, 4PCC therapy may be a reasonable treatment option in patients on rivaroxaban therapy who present with $\mathrm{AAICH}$.

Apixaban. Similar to rivaroxaban, the strategy to reverse apixaban in $\mathrm{AAICH}$ is unclear, since there is a lack of experimental and clinical data. In addition to discontinuing apixaban, activated charcoal may be administered to patients who have taken their last apixaban dose within the previous 3 hours. ${ }^{55}$ As with rivaroxaban, patients who require apixaban reversal are not candidates for dialysis, since a majority of apixaban is bound to plasma proteins. ${ }^{55}$ To date, there are no human studies of reversal agents in patients who require rapid apixaban reversal. In a rabbit model of bleeding, apixaban treatment resulted in increased blood loss; lengthened bleeding time (BT), prothrombin time (PT), and clotting time; and decreased thrombin formation. ${ }^{56}$ Subsequent treatment with PCC or rFVIla helped reduce BT, PT, clotting time, and thrombin formation time; however, only PCC reduced blood loss. ${ }^{56}$

\section{ICH Guideline Recommendations}

The American Heart Association (AHA) and the American Stroke Association (ASA) jointly published guidelines for the management of spontaneous $\mathrm{ICH},{ }^{57}$ most recently in 2010. These guidelines also include recommendations on reversal strategies of $\mathrm{AAICH}$; however, the guidelines were written before the approval of the targeted OACs. For all types of $\mathrm{ICH}$, the key recommendations are to maintain a mean arterial pressure of less than $130 \mathrm{mmHg}$ and a cerebral perfusion pressure (mean arterial blood pressure minus intracranial pressure) of at least $60 \mathrm{mmHg}$. However, investigation is ongoing (e.g., INTERACT 1 and 2 and ATACH 1 and 2 trials) on the role of more aggressive and early blood pressure (BP) reduction to limit $\mathrm{ICH}$ growth and its effect on outcome. ${ }^{58-60}$ INTERACT 1 found that early intensive BP lowering seemed to attenuate hematoma growth when compared with a more conservative guideline-based policy. ${ }^{59}$ INTERACT 2 failed to show a significant reduction in the rate of the primary outcome of death or major disability (modified Rankin Scale [mRS] Score 3-6), with early intensive BP lowering; however, there was a significant favorable shift in the secondary endpoint of distribution of $\mathrm{mRS}$ scores among treated patients. There were also more patients whose conditions were normal or near normal (mRS Score 0-1) at 90 days. Reassuringly, there were no differences in the rate of death or numbers of serious adverse events between the 2 groups. The Antihypertensive Treatment of Acute Cerebral Haemorrhage (ATACH) 2 trial, which is using similar BP targets to INTERACT, should shed further light on the benefit of early aggressive BP lowering in patients with spontaneous $\mathrm{ICH}$. The results of these studies may further refine BP management. ${ }^{61-63}$ It is important to realize that recommendations for $\mathrm{BP}$ control and $\mathrm{AAICH}$ are based on data for acute spontaneous $\mathrm{ICH}$ and not specifically for $\mathrm{AAICH}$; hence the recommendations should be judged accordingly. Furthermore, in $\mathrm{AAICH}$, when trying to maintain goal mean arterial pressure and cerebral perfusion pressure, FFP may affect volume restoration and so adversely affect blood pressure. The AHA recommends an emergent brain CT scan when AAICH is suspected. Level 2 recommendations call for a contrast-enhanced CT or a CT angiogram to assess the presence of a spot sign that, when present, is associated with the risk of hematoma expansion. ${ }^{64}$ The INR is essential to obtain a quantitative measure of warfarin use and intensity of anticoagulation. In some studies, higher INR levels are correlated with increased likelihood of hematoma expansion and 
less favorable outcomes, ${ }^{50}$ but this finding is not consistent, since other studies demonstrate no association between normalization of INR and hematoma expansion or mortality. ${ }^{9,50}$

In patients who have $\mathrm{AAICH}$, particularly those with warfarin-associated $\mathrm{ICH}$, vitamin $\mathrm{K}(10 \mathrm{mg})$ is recommended along with administration of FFP and PCCs to immediately reverse INR, restart vitamin K-dependent coagulation factor synthesis, and achieve hemostasis. Once the patient has been stabilized, the need to restart anticoagulation should be addressed.

\section{Restarting Oral Anticoagulation Therapy}

There is controversy about when to reinitiate OAC therapy following $\mathrm{AAICH}$, and neurosurgeons generally are more hesitant to do so than cardiologists. ${ }^{35}$ Although the concern of recurrent hemorrhage is real, this must be balanced against the risk of an ischemic stroke or venous thromboembolism, and in particular PE. ${ }^{35}$ The decision to restart anticoagulation should be based on the patient's medical history, physiology, and the need to balance the risk of thrombotic complications versus bleeding, either ongoing or recurrent.

A common indication for warfarin stroke prevention is found in patients with nonvalvular AF. The $2010 \mathrm{AHA} /$ ASA guidelines for the management of spontaneous $\mathrm{ICH}$ suggest that long-term anticoagulation treatment be avoided in nonvalvular AF following $\mathrm{AAICH}$, given the risk of $\mathrm{ICH}$ recurrence. Instead, the guidelines recommend antiplatelet therapy. ${ }^{57}$ However, other patient characteristics can be considered when deciding whether to restart OAC therapy. Follow-up studies suggest that a lobar ICH location has a greater 2-year risk of $\mathrm{ICH}$ recurrence than a deep hemispheric hemorrhage ( $22 \%$ vs $4 \%) .{ }^{65}$ Therefore, in patients considered at a high risk for recurrent hemorrhage (e.g., those with a large lobar $\mathrm{ICH}$ ), restarting OAC therapy may be a relative contraindication. However, in patients with a low risk of recurrent hemorrhage but at a high risk of stroke (e.g., those patients with a $\mathrm{CHADS}_{2}$ (Cardiac failure, Hypertension, Age, Diabetes, Stroke) Score $\geq 1$, restarting $O A C$ may be warranted. In addition, restarting OAC therapy with a targeted OAC may also be considered, since these agents are reported to have a lower risk of $\mathrm{AAICH}$ than warfarin. ${ }^{32-34}$ In making this decision, the patient's age and other comorbidities need to be considered and, depending on those characteristics, it is reasonable to consider restarting therapy with the targeted OACs sooner or as an alternative to warfarin. However, the onset of action of the targeted OACs is more rapid than that of warfarin, which should also be taken into account. ${ }^{35}$

Expert opinion before 2010 recommended restarting warfarin 7 to 14 days after AAICH. ${ }^{16}$ However, more recent publications suggest waiting 10 to 30 weeks after $\mathrm{AAICH}$ to restart warfarin may be more appropriate for some patients. ${ }^{66}$ This recommendation is based on a large multicenter, retrospective cohort analysis of 2869 patients who presented with warfarin-associated $\mathrm{ICH}$. Hazard ratios were calculated for recurrent AAICH (5.6; 95\% confidence index [Cl] 1.8-17.2) and ischemic stroke $(0.11 ; 95 \% \mathrm{Cl} 0.014-0.890)$. By plotting combined treatment risk over time, it was determined that the optimal time to resume anticoagulation following a warfarin-associated ICH was 10 to 30 weeks. ${ }^{66,67}$ Whether these data can be applied to patients who take targeted OACs is uncertain. Furthermore, this delay in restarting OAC should be balanced against why the OAC was needed in the first place. ${ }^{68}$ For example, if a patient has a history of DVT and is close to the end of treatment, it may be reasonable not to restart anticoagulation at all. By contrast, in a patient with a mechanical heart valve or left ventricular assist devices, it may be prudent to restart anticoagulation earlier. For example, in a retrospective study of 330 patients with left ventricular assist devices, Wilson et al. found that $11 \%$ developed $\mathrm{AAICH} .{ }^{69}$ Aspirin and warfarin were discontinued in $47 \%$ and $61 \%$ of patients, respectively, and resumed within a median of 6 days for aspirin and 10.5 days for warfarin. No cases of rehemorrhage occurred, suggesting that restarting anticoagulation 7 to 14 days after $\mathrm{ICH}$ may be safe. ${ }^{69}$ Expert opinion further suggests that if the patient's INR is corrected to normal using PCCs and the patient is at significant thrombotic risk, then a low-molecular-weight heparin or even subcutaneous heparin starting a couple of days after $\mathrm{ICH}$ onset can be given and definitive anticoagulation therapy can be resumed after 10 to 30 weeks. . $6,67,70,71^{-1}$ 


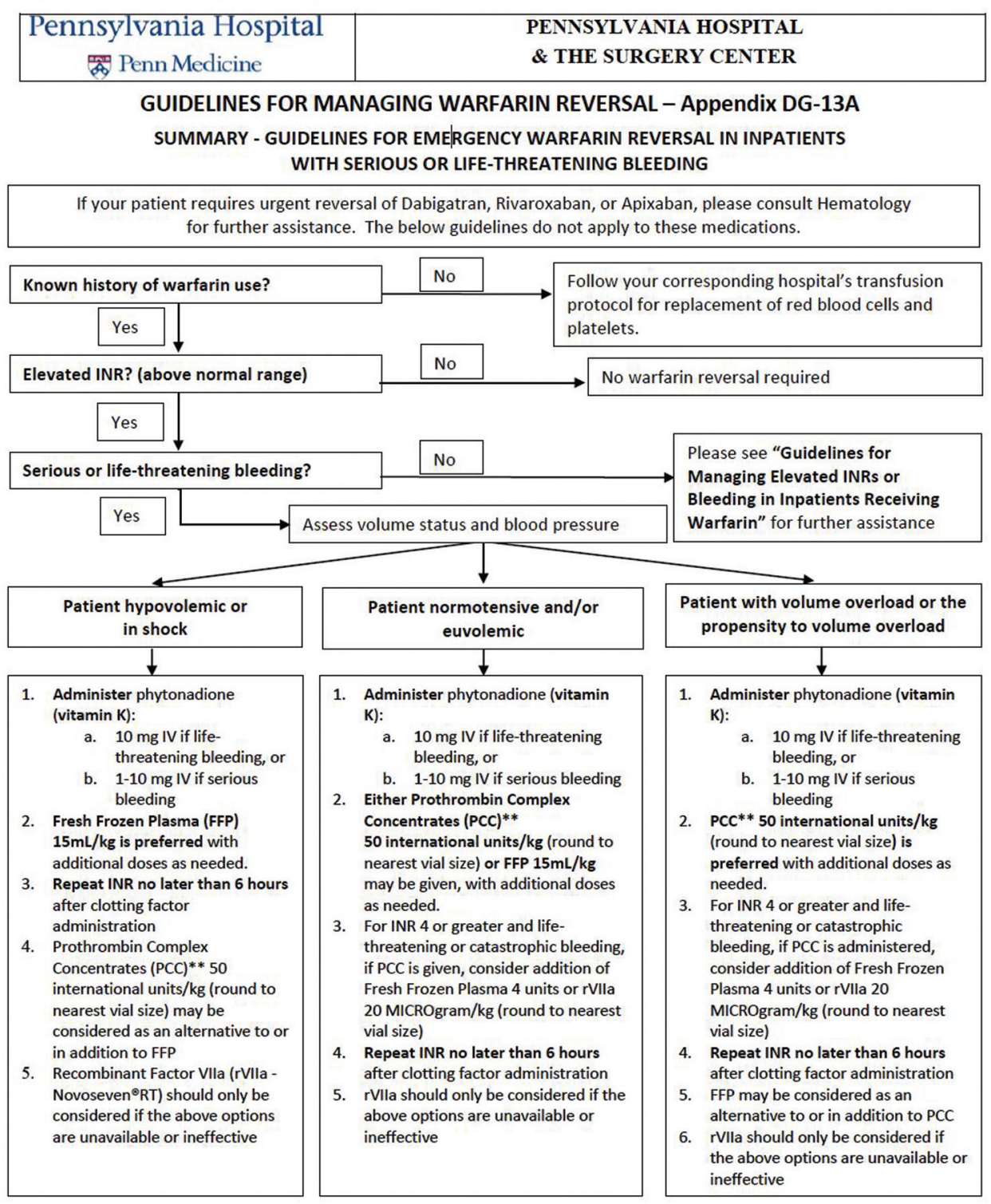

Figure 3: Example of an Institutional Protocol for AAICH management

This institutional protocol exemplifies the algorithmic pathway for the emergent management of life-threatening bleeding in patients taking warfarin. Courtesy of Pennsylvania Hospital, Philadelphia PA.

\section{Surgery for AAICH}

Treatment of $\mathrm{AAICH}$ ranges from best medical therapy to aggressive management including a variety of surgical techniques that may include: 1) an intracranial pressure monitor; 2) an external ventricular drain; 3) craniotomy with surgical clot evacuation using either conventional techniques or stereotactic guided techniques; 4) decompressive craniectomy; or, more recently, 5) minimally invasive surgery (MIS). While the role of these various techniques has been assessed in cases of spontaneous $\mathrm{ICH}$, there is limited study of how surgery may influence the outcome in $\mathrm{AAICH}$, and published guidelines and recommendations, in general, address non-anticoagulant-associated $\mathrm{ICH}$. Furthermore, patients with AAICH are excluded from 
Table 3: Sample Physician Orders for AAICH Management ${ }^{70,71}$

\begin{tabular}{|c|}
\hline The patient must meet the following criteria: \\
\hline - Documented ICH on CT scan \\
\hline - INR $\geq 2$ on warfarin therapy \\
\hline 1. Discontinue warfarin \\
\hline 2. FFP -2 units \\
\hline - FFP transfusion: give 2 units IV STAT x 1 \\
\hline $\begin{array}{l}\text { 3. Phytonadione (vitamin K) } 10 \mathrm{mg} \text { IVPB in } 50 \mathrm{ml} \text { of NS } \times 1 \text { over } 30 \\
\text { min }\end{array}$ \\
\hline - Recheck PT/INR in 30 min; if still elevated, administer PCC \\
\hline
\end{tabular}

An example of physician orders based on presence of an $\mathrm{ICH}$ on the $\mathrm{CT}$ scan and an INR $>2$.

Abbreviations: IVBP = intravenous piggy-back; NS = normal saline.

clinical trials of surgical intervention in $\mathrm{ICH} .{ }^{57,72,73}$ Similarly, patients with cerebellar hematomas have largely been excluded from clinical trials.

Traditionally, open craniotomy and hematoma evacuation has been the mainstay of surgical ICH management. However, multiple trials have failed to show a benefit to neurologic function associated with craniotomy. There are several reasons for these failures, including the marked heterogeneity in patient- and $\mathrm{ICH}$-specific factors, in treatment, and in definitions of care (e.g., what defines early intervention?). One of the largest randomized clinical trials in which open craniotomy was compared with nonsurgical treatment was STICH I. This trial included 1033 patients. Favorable outcomes were observed in $26 \%$ of patients who had surgery and in $24 \%$ of patients given best medical care. ${ }^{72}$ Subsequent subgroup analysis suggested that patients with a superficial $\mathrm{ICH}$ and no intraventricular hemorrhage (IVH) benefited from surgery. ${ }^{74}$ In a smaller randomized clinical trial that included 108 patients and randomized patients to early surgery $(<8$ hours) or best medical management, Pantazis et al. observed that surgery improved outcome, particularly when the Glasgow Coma Scale (GCS) score was >8, $\mathrm{ICH}$ volume was $<80 \mathrm{ml}$, or the $\mathrm{ICH}$ was subcortical. ${ }^{75}$ Together these studies suggested a benefit to cranioto- my in select patients. This impression was confirmed in a meta-analysis in which individual patient data from 8 of the 14 randomized clinical trials suggested a benefit to surgery when randomization occurred within 8 hours of symptom onset, the $\mathrm{ICH}$ volume was $20 \mathrm{ml}$ to $50 \mathrm{ml}$, the GCS score was between 9 and 12, or the patient was between 50 and 69 years old. ${ }^{76}$

STICH II, a multicenter randomized clinical trial, was designed to test the hypothesis that early surgery would benefit patients with a superficial ICH and without IVH. However, surgical outcomes were similar to patients who received best medical management, and $59 \%$ of surgical and $62 \%$ of nonsurgical patients had unfavorable outcomes. ${ }^{77}$ While some meta-analytic data suggest a potential benefit to craniotomy in select $\mathrm{ICH}$ patients, it is important to remember that these trials included various patient groups and surgical interventions. $^{76,78}$ Furthermore, these data cannot be applied to $\mathrm{AAICH}$, since these patients were largely excluded from the trials. There are several unanswered questions about open craniotomy (e.g., patient selection and what constitutes early surgery). Nevertheless, current recommendations include the following: 1) For most AAICH patients the role of surgical evacuation is uncertain. 2) Rapid surgical removal is indicated in patients who have a cerebellar hemorrhage who are deteriorating rapidly or who have brainstem compression and hydrocephalus. A ventricular drain alone is not sufficient in these patients. 3) Early hematoma evacuation through a standard craniotomy should be considered for patients who have a lobar $\mathrm{ICH}>30 \mathrm{ml}$ in volume and within $1 \mathrm{~cm}$ of the brain surface..$^{57,64}$

Minimally invasive surgery for AAICH. The development of MIS for $\mathrm{ICH}$ predates the randomized clinical trials in open craniotomy for $\mathrm{ICH}$, but the trial results and recent advances in stereotactic navigation have led to renewed interest in the role of MIS for AAICH. ${ }^{16,73,79-82}$ These techniques use stereotactic guidance combined with either thrombolytic enhanced or endoscopic enhanced clot aspiration. In addition, intraoperative imaging (e.g., use of intraoperative CT) can help guide clot evacuation. A potential advantage of minimally invasive clot removal is that deep putaminal or thalamic hemorrhages may be accessible, and there is less damage to the overlying brain. As with open 
surgery, the optimal time to maximum clot removal remains unclear.

Several studies have examined the role of MIS in ICH. In 1989 Auer et al. randomized 100 patients with spontaneous ICH (subcortical, putaminal, and thalamic $\mathrm{ICH}$ ) to endoscopic evacuation or medical treatment. In subgroup analysis only surgical patients with subcortical bleeds had reduced mortality, and surgical patients with ICHs $<50 \mathrm{ml}$ had better functional recovery, but not reduced mortality, than medically treated patients. ${ }^{83}$ Since then MIS techniques have continued to evolve. Further modifications include thrombolytic infusion through stereotactically placed catheters. In another randomized clinical trial, the Stereotactic Treatment of Intracerebral Hematoma by means of a Plasminogen Activator (SICHPA) trial, Teernstra et al. observed that $\mathrm{ICH}$ volume was reduced by $10 \%$ to $20 \%$ after stereotactic treatment and $\mathrm{ICH}$ aspiration after application of plasminogen activating factor. However, there was no survival advantage at 180 days and neurological outcome was similar to that of patients treated with medical management. ${ }^{84}$ In other clinical studies, the feasibility, safety and potential benefit of subacute stereotactic aspiration and endoscopic $\mathrm{ICH}$ evacuation or evacuation using pharmacological thrombolysis or sono-thrombolysis has been observed. ${ }^{81,85-87}$ Two trials that use different techniques to evacuate $\mathrm{ICH}$ are ongoing: 1) Minimally Invasive Surgery plus recombinant Tissue plasminogen activator (rt-PA) for $\mathrm{ICH}$ Evacuation (MISTIE) and 2) Intraoperative Computed Tomography-Guided Endoscopic Surgery (ICES). MISTIE relies on the accurate placement of a drain, administration of rt-PA, and gradual hematoma volume reduction over 72 hours, whereas ICES is a rapid endoscopic ICH evacuation.

Data from the MISTIE and ICES trials were presented at the International Stroke Conference in February 2013 in Honolulu. In MISTIE, data analyzed at 365 days indicate that patients randomized to the rt-PA group had a shorter hospital stay and a small upward shift across the modified Rankin Scale (mRS). In ICES, an immediate $70 \%$ clot volume reduction was observed with endoscopic ICH evacuation, which was associated with improved clinical outcome (mRS Score 3) at 180 days ${ }^{88}$ Subsequent analysis of patients treated with a
MIS approach and rtPA have shown that reduction in $\mathrm{ICH}$ volume is associated with reduced perihematomal edema (PHE). ${ }^{89}$ The relationship between PHE and long-term tissue injury is complex but PHE is associated with poor outcome, whereas an increase in PHE can cause a decline in neurologic status. Together these studies suggest there is a potential benefit to MIS techniques for AAICH. However, the patients who seem to benefit most from MIS techniques are very similar to those who benefit from craniotomy, ie, patients with superficial ICH, GCS Score $\geq 9$, ICH volume between $25 \mathrm{ml}$ and $40 \mathrm{ml}$, and surgery within 72 hours of symptom onset. Whether these data about MIS for ICH can or should be extrapolated to patients with $\mathrm{AAICH}$ is uncertain.

\section{Institutional Protocols}

AAICH is common. However, the development and use of general guidelines and specific institutional protocols of evidence-based clinical pathways for reversal of AAICH and their influence on outcome have not been well studied, in part because some treatments for AAICH are not FDA approved, and as a result are administered off label, and patient care varies across care centers and among physicians within the same institution. Several lines of evidence, however, suggest that development of institutional polices for $\mathrm{ICH}$ and specifically for AAICH has the potential to enhance patient outcomes. Such a protocol requires communication and collaboration among the emergency room, neurologists, the intensivists, and, ideally, neurointensivists, neurosurgeons, rehabilitation physicians, and nursing staff, among others. Studies suggest that patients with $\mathrm{ICH}$ admitted to neurocritical care units have better outcomes than those admitted to general medical intensive care units. ${ }^{90}$

These institutional guidelines can help delineate protocols for all medical personnel involved in treating the patient with $\mathrm{ICH}$ and $\mathrm{AAICH}$. These protocols can be important to help guide decision-making to provide the appropriate clinical care to ensure the best clinical outcomes for patients. Institutional protocols can be written as a logical flow diagram. Hence at a specific institution physician orders may resemble the material 
presented in Table $3^{70,71}$ and the flow diagram may resemble that shown in Figure 3. Several national organizations (eg, AHA, Neurocritical Care Society [NCS]) also have provided ICH guidelines. ${ }^{91}$ The most recent of these are the NCS guidelines, which are a component of emergency neurologic life support (ENLS) and are available online (www.neurocriticalcare.org/ enls-protocols).

\section{Conclusions}

As the population ages and more patients are placed on long-term anticoagulation including warfarin and NOACs, AAICHs have become and will continue to become more prevalent. Patients on warfarin therapy have a 7 - to 10-fold increased risk of developing $\mathrm{ICH}$. Warfarin-associated ICHs occur most commonly within the conventional INR range of 2 to 3.5 , and even at these therapeutic levels, the ICH can expand. There is a well-described association between $\mathrm{ICH}$ volume and outcome, with poor outcome significantly more likely when the $\mathrm{ICH}$ is greater than $30 \mathrm{ml} .{ }^{67}$ The implications of preliminary analysis from the MISTIE and ICES trials are consistent with this finding, since they suggest that with treatment, the greater the reduction in clot size, the better the patient outcome. Hence for patients with $\mathrm{AAICH}$ it is important to develop reliable and costeffective treatment methods that reduce clot expansion and so potentially reduce morbidity and mortality.

Treatment centers should have protocols in place that allow for effective decision-making and clear communication across the spectrum of medical personnel who treat patients with AAICH. Guidelines published by the AHA provide recommendations on care for $\mathrm{ICH}$ but not specifically for $\mathrm{AAICH} .{ }^{56}$ For $\mathrm{AAICH}$ the recommendations currently advocate administration of vitamin K, FFP, and 3-factor PCCs. The 4PCCs are new to the US market, so the recommendations may soon change to include these newly approved drugs. PCCs may have an advantage in select patients over FFP since there is no need for blood typing or thawing and because of their much smaller infusion volumes. In addition, the treatment landscape will need to adapt to the management of $\mathrm{AAICH}$ in patients taking a targeted $\mathrm{OAC}$ instead of warfarin; in these patients vitamin $\mathrm{K}$ is not indicated and the roles of FFP, rFVIla, and PCCs require further study. The decision to recommend a patient for surgery depends on an individualized basis of care, as there is some evidence that surgical intervention is beneficial in select patients.

\section{Author Disclosures}

Peter Le Roux, MD, FACS

Retained Consultant: Integra LifeSciences; Codman \& Shurtleff, Inc.; Synthes, Inc.

Speakers Bureau: Integra LifeSciences

Contracted Research: Integra LifeSciences

Charles V. Pollack, Jr, MA, MD, FACEP

Consultant: Astra-Zeneca; Boehringer Ingelheim Pharmaceuticals, Inc; Bristol-Myers Squibb; Daiichi Sankyo, Inc; Janssen Pharmaceuticals, Inc; Pfizer Inc; SanofiAventis U.S. LLC.

Scientific Directors, Melissa Milan, MD, and Alisa Schaefer, PhD have no financial conflicts to disclose.

Paradigm Medical Communications, LLC staff members have no financial conflicts to disclose.

\section{Corresponding author:}

Peter LeRoux, M.D.

The Brain and Spine Center

Suite 370, Medical Science Building

Lankenau Medical Center

100 E. Lancaster Avenue

Wynnewood PA 19096

LeRouxP@MLHS.org 


\section{References}

1. US Food and Drug Administration. FDA approves Kcentra for the urgent reversal of anticoagulation in adults with major bleeding. April 29, 2013. Available at: www.fda.gov/ NewsEvents/Newsroom/Pressannouncements/ ucm350026.htm. Accessed January 30, 2014.

2. Bejot Y, Cordonnier C, Durier J, et al. Intracerebral haemorrhage profiles are changing: results from the Dijon population-based study. Brain. 2013;136:658-664.

3. Cotte FE, Chaize G, Kachaner I, et al. Incidence and Cost of Stroke and Hemorrhage in Patients Diagnosed with Atrial Fibrillation in France. J Stroke Cerebrovasc Dis. 2013 Oct. [Epub ahead of print]

4. Howard G, Cushman M, Howard VJ, et al. Risk factors for intracerebral hemorrhage: the REasons for geographic and racial differences in stroke (REGARDS) study. Stroke. 2013;44:1282-1287.

5. van Asch CJ, Luitse MJ, Rinkel GJ, et al. Incidence, case fatality, and functional outcome of intracerebral haemorrhage over time, according to age, sex, and ethnic origin: a systematic review and meta-analysis. Lancet Neurol. 2010;9:167-176.

6. Bechtel BF, Nunez TC, Lyon JA, et al. Treatments for reversing warfarin anticoagulation in patients with acute intracranial hemorrhage: a structured literature review. Int J Emerg Med. 2011;4(1):40.

7. Flaherty ML, Adeoye O, Sekar P, et al. The challenge of designing a treatment trial for warfarin-associated intracerebral hemorrhage. Stroke. 2009;40:1738-1742.

8. Cucchiara B, Messe S, Sansing L, et al. Hematoma growth in oral anticoagulant related intracerebral hemorrhage. Stroke. 2008;39:29932996.

9. Dowlatshahi D, Butcher KS, Asdaghi N, et al. Poor prognosis in warfarin-associated intracranial hemorrhage despite anticoagulation reversal. Stroke. 2012;43:1812-1817.

10. Lovelock CE, Molyneux AJ, Rothwell PM. Change in incidence and aetiology of intracere- bral haemorrhage in Oxfordshire, UK, between 1981 and 2006: a population-based study. Lancet Neurol. 2007;6:487-493.

11. Cervera A, Amaro S, Chamorro A. Oral anticoagulant-associated intracerebral hemorrhage. $J$ Neurol. 2012;259:212-224.

12. Camm AJ, Lip GY, De Caterina R, et al: 2012 focused update of the ESC Guidelines for the management of atrial fibrillation: an update of the 2010 ESC Guidelines for the management of atrial fibrillation-developed with the special contribution of the European Heart Rhythm Association. Europace. 2012;14:1385-1413.

13. Ansell J, Hirsh J, Hylek E, et al. Pharmacology and management of the vitamin $\mathrm{K}$ antagonists: American College of Chest Physicians Evidence-Based Clinical Practice Guidelines (8th Edition). Chest. 2008;133:160S-198S.

14. Rubboli A, Becattini C, Verheugt FW. Incidence, clinical impact and risk of bleeding during oral anticoagulation therapy. World J Cardiol. 2011;3(11):351-358.

15. Jonas DE, Bryant Shilliday B, Laundon WR, et al. Patient time requirements for anticoagulation therapy with warfarin. Med Decis Making. 2010;30:206-216.

16. Aguilar MI, Hart RG, Kase CS, et al. Treatment of warfarin-associated intracerebral hemorrhage: literature review and expert opinion. Mayo Clin Proc. 2007;82:82-92.

17. Camm AJ, Kirchhof P, Lip GY, et al. Guidelines for the management of atrial fibrillation: the Task Force for the Management of Atrial Fibrillation of the European Society of Cardiology (ESC). Europace. 2010;12:1360-1420.

18. Eriksson BI, Borris LC, Friedman RJ, et al. Rivaroxaban versus enoxaparin for thromboprophylaxis after hip arthroplasty. $N$ Engl J Med. 2008;358:2765-2775.

19. Lassen MR, Laux V. Emergence of new oral antithrombotics: a critical appraisal of their clinical potential. Vasc Health Risk Manag. 2008;4:1373-1386.

20. van Walraven C, Jennings A, Oake N, et al. Effect of study setting on anticoagulation control: a systematic review and metaregression. Chest. 2006;129:1155-1166. 
21. Pradaxa ${ }^{\circledR}$ (dabigatran etexilate mesylate). Package insert. Boehringer Ingelheim, Ingelheim am Rhein, Germany. 11/12.

22. Xarelto ${ }^{\circledR}$ (rivaroxaban). Package insert. Janssen Pharmaceuticals, Inc., Titusville, NJ, USA. $3 / 14$.

23. Eliquis ${ }^{\circledR}$ (apixaban). Package insert. BristolMyers Squibb, New York, NY, USA. 12/12.

24. Nutescu E. Apixaban: a novel oral inhibitor of factor Xa. Am J Health Syst Pharm. 2012;69(13):1113-1126.

25. Ageno W, Gallus AS, Wittkowsky A, et al, American College of Chest Physicians. Oral anticoagulant therapy: Antithrombotic Therapy and Prevention of Thrombosis, 9th ed: American College of Chest Physicians EvidenceBased Clinical Practice Guidelines. Chest. 2012;141(2 Suppl): e44S-88S.

26. Levine MN, Raskob G, Landefeld S, et al. Hemorrhagic complications of anticoagulant treatment. Chest. 2001;119:108S-121S.

27. Wittkowsky AK. Novel oral anticoagulants and their role in clinical practice. Pharmacotherapy. 2011;31:1175-1191.

28. Eriksson BI, Quinlan DJ, Weitz JI. Comparative pharmacodynamics and pharmacokinetics of oral direct thrombin and factor xa inhibitors in development. Clin Pharmacokinet. 2009;48:1-22.

29. Awad AJ, Walcott BP, Stapleton CJ, et al. Dabigatran, intracranial hemorrhage, and the neurosurgeon. Neurosurg Focus. 2013;34:E7.

30. Bereznicki LR, Peterson GM. New antithrombotics for atrial fibrillation. Cardiovasc Ther. 2010;28:278-286.

31. Fawole A, Daw HA, Crowther MA. Practical management of bleeding due to the anticoagulants dabigatran, rivaroxaban, and apixaban. Cleve Clin J Med. 2013;80:443-451.

32. Connolly SJ, Ezekowitz MD, Yusuf S, et al. Dabigatran versus warfarin in patients with atrial fibrillation. N Engl J Med. 2009;361:11391151.

33. Patel MR, Mahaffey KW, Garg J, et al. Rivaroxaban versus warfarin in nonvalvular atrial fibrillation. N Engl J Med. 2011;365:883-891.

34. Granger CB, Alexander JH, McMurray JJ, et al.
Apixaban versus warfarin in patients with atrial fibrillation. N Engl J Med. 2011;365:981-992.

35. El Ahmadieh TY, Aoun SG, Daou MR, et al. New-generation oral anticoagulants for the prevention of stroke: Implications for neurosurgery. J Clin Neurosci. 2013;20:1350-1356.

36. Flibotte JJ, Hagan N, O’Donnell J, et al. Warfarin, hematoma expansion, and outcome of intracerebral hemorrhage. Neurology. 2004;63:1059-1064.

37. Rosand J, Eckman MH, Knudsen KA, et al. The effect of warfarin and intensity of anticoagulation on outcome of intracerebral hemorrhage. Arch Intern Med. 2004;164:880-884.

38. Masotti L, Di Napoli M, Godoy DA, et al. The practical management of intracerebral hemorrhage associated with oral anticoagulant therapy. Int J Stroke. 2011;6:228-240.

39. Diringer MN, Zazulia AR. Hemostatic therapy should be used for acute treatment of anticoagulation-related intracerebral hemorrhage. Stroke. 2012;43:2535-2536.

40. Dentali F, Marchesi C, Pierfranceschi MG, et al. Safety of prothrombin complex concentrates for rapid anticoagulation reversal of vitamin $\mathrm{K}$ antagonists. A meta-analysis. Thromb Haemost. 2011;106:429-438.

41. Switzer JA, Rocker J, Mohorn P, et al. Clinical experience with three-factor prothrombin complex concentrate to reverse warfarin anticoagulation in intracranial hemorrhage. Stroke. 2012;43:2500-2502.

42. Voils SA, Baird B. Systematic review: 3-factor versus 4-factor prothrombin complex concentrate for warfarin reversal: does it matter? Thromb Res. 2012;130:833-840.

43. Kerebel D, Joly LM, Honnart D, et al. A French multicenter randomised trial comparing two dose-regimens of prothrombin complex concentrates in urgent anticoagulation reversal. Crit Care. 2013;17:R4.

44. Sarode R, Milling TJ Jr, Refaai MA, et al. Efficacy and Safety of a 4-Factor Prothrombin Complex Concentrate in Patients on Vitamin K Antagonists Presenting With Major Bleeding: A Randomized, Plasma-Controlled, Phase IIIb Study. Circulation. 128:1234-1243. 
45. Hickey M, Gatien M, Taljaard M, et al. Outcomes of urgent warfarin reversal with frozen plasma versus prothrombin complex concentrate in the emergency department. Circulation. 2013;128:360-364.

46. Mayer SA, Brun NC, Begtrup K, et al. Efficacy and safety of recombinant activated factor VII for acute intracerebral hemorrhage. $N$ Engl J Med. 2008;358:2127-2137.

47. Diringer MN, Skolnick BE, Mayer SA, et al. Thromboembolic events with recombinant activated factor VII in spontaneous intracerebral hemorrhage: results from the Factor Seven for Acute Hemorrhagic Stroke (FAST) trial. Stroke. 2010;41:48-53.

48. Robinson MT, Rabinstein AA, Meschia JF, et al. Safety of recombinant activated factor VII in patients with warfarin-associated hemorrhages of the central nervous system. Stroke. 2010;41:1459-1463.

49. Dickneite G. Prothrombin complex concentrate versus recombinant factor VIIa for reversal of coumarin anticoagulation. Thromb Res. 2007;119:643-651.

50. Selim MH, Molina CA. The role of hemostatic therapy in anticoagulation-associated intracerebral hemorrhage: intuition versus evidence. Stroke. 2012;43:2539-2540.

51. Lauer A, Pfeilschifter W, Schaffer CB, et al. Intracerebral haemorrhage associated with antithrombotic treatment: translational insights from experimental studies. Lancet Neurol. 2013;12:394-405.

52. Chang DN, Dager WE, Chin AI. Removal of dabigatran by hemodialysis. Am J Kidney Dis. 2013;61:487-489.

53. Eerenberg ES, Kamphuisen PW, Sijpkens MK, et al. Reversal of rivaroxaban and dabigatran by prothrombin complex concentrate: a randomized, placebo-controlled, crossover study in healthy subjects. Circulation. 2011;124:15731579.

54.Zhou W, Schwarting S, Illanes S, et al. Hemostatic therapy in experimental intracerebral hemorrhage associated with the direct thrombin inhibitor dabigatran. Stroke. 2011;42:35943599.
55. Steiner T, Bohm M, Dichgans M, et al. Recommendations for the emergency management of complications associated with the new direct oral anticoagulants (DOACs), apixaban, dabigatran and rivaroxaban. Clin Res Cardiol. 2013;102:399-412.

56. Martin AC, Le Bonniec B, Fischer AM, et al. Evaluation of recombinant activated factor VII, prothrombin complex concentrate, and fibrinogen concentrate to reverse apixaban in a rabbit model of bleeding and thrombosis. Int J Cardiol. 2013;168(4):4228-4233.

57. Morgenstern LB, Hemphill JC 3rd, Anderson $\mathrm{C}$, et al. Guidelines for the management of spontaneous intracerebral hemorrhage: a guideline for healthcare professionals from the American Heart Association/American Stroke Association. Stroke. 2010;41:2108-2129.

58. Anderson CS, Huang Y, Arima H, et al. INTERACT Investigators. Effects of early intensive blood pressure-lowering treatment on the growth of hematoma and perihematomal edema in acute intracerebral hemorrhage: the Intensive Blood Pressure Reduction in Acute Cerebral Haemorrhage Trial (INTERACT). Stroke. 2010;41(2):307-312.

59. Arima H, Huang Y, Wang JG, et al; INTERACT1 Investigators. Earlier blood pressurelowering and greater attenuation of hematoma growth in acute intracerebral hemorrhage: INTERACT pilot phase. Stroke. 2012;43(8):22362238.

60. Anderson CS, Heeley E, Huang Y, et al for the INTERACT2 Investigators. Rapid blood-pressure lowering in patients with acute intracerebral hemorrhage. N Engl J Med. 2013;368:23552365.

61. Arima H, Anderson CS, Wang JG, et al. Lower treatment blood pressure is associated with greatest reduction in hematoma growth after acute intracerebral hemorrhage. Hypertension. 2010;56:852-858.

62. Grise EM, Adeoye O. Blood pressure control for acute ischemic and hemorrhagic stroke. Curr Opin Crit Care. 2012;18:132-138.

63. Qureshi AI, Palesch YY, Martin R, et al. Effect of systolic blood pressure reduction on he- 
matoma expansion, perihematomal edema, and 3-month outcome among patients with intracerebral hemorrhage: results from the antihypertensive treatment of acute cerebral hemorrhage study. Arch Neurol. 2010;67:570-576.

64 . Wada H. [Study on guidelines for the treatment of DIC]. Rinsho Ketsueki. 2007;48:377-385.

65. Paciaroni M, Agnelli G. Should oral anticoagulants be restarted after warfarin-associated intracerebral haemorrhage in patients with atrial fibrillation? Thromb Haemost. 2014;111.

66. Marsh EB, Gottesman RF. Brain hemorrhage: restarting anticoagulation after intracranial hemorrhage. Nat Rev Neurol. 2011;7:130-132.

67. Majeed A, Kim YK, Roberts RS, et al. Optimal timing of resumption of warfarin after intracranial hemorrhage. Stroke. 2010;41:2860-2866.

68. Degos V, Westbroek EM, Lawton MT, et al. Perioperative management of coagulation in nontraumatic intracerebral hemorrhage. Anesthesiology. 2013;119:218-227.

69. Wilson TJ, Stetler WR, Al-Holou WN, et al. Management of intracranial hemorrhage in patients with left ventricular assist devices. $\mathrm{J} \mathrm{Neu-}$ rosurg. 2013;118:1063-1068.

70. Furie KL, Goldstein LB, Albers GW, et al. Oral antithrombotic agents for the prevention of stroke in nonvalvular atrial fibrillation: a science advisory for healthcare professionals from the American Heart Association/American Stroke Association. Stroke. 2012;43:3442-3453.

71. Holbrook A, Schulman S, Witt DM, et al. Evidence-based management of anticoagulant therapy: Antithrombotic Therapy and Prevention of Thrombosis, 9th ed: American College of Chest Physicians Evidence-Based Clinical Practice Guidelines. Chest. 2012;141:e152S184 S.

72. Mendelow AD, Gregson BA, Fernandes HM, et al. Early surgery versus initial conservative treatment in patients with spontaneous supratentorial intracerebral haematomas in the International Surgical Trial in Intracerebral Haemorrhage (STICH): a randomised trial. Lancet. 2005;365:387-397.

73. Morgan T, Zuccarello M, Narayan R, et al. Preliminary findings of the minimally-invasive surgery plus rtPA for intracerebral hemorrhage evacuation (MISTIE) clinical trial. Acta Neurochir Suppl. 2008;105:147-151.

74. Bhattathiri PS, Gregson B, Prasad KSM, Mendelow AD. Intraventricular hemorrhage and hydrocephalus after spontaneous intracerebral hemorrhage: results from the STICH trial. Acta Neurochir Suppl. 2006;96:65-68.

75. Pantazis G, Tsitsopoulos P, Mihas C, et al. Early surgical treatment vs conservative management for spontaneous supratentorial intracerebral hematomas: A prospective randomized study. Surg Neurol. 2006;66(5):492-501.

76. Gregson B a, Broderick JP, Auer LM, et al. Individual patient data subgroup meta-analysis of surgery for spontaneous supratentorial intracerebral hemorrhage. Stroke. 2012;43(6):14961504.

77. Mendelow AD, Gregson BA, Rowan EN, et al. Early surgery versus initial conservative treatment in patients with spontaneous supratentorial lobar intracerebral haematomas (STICH II): a randomised trial. Lancet. 2013;382:397-408.

78. Prasad K, Mendelow AD, Gregson B. Surgery for primary supratentorial intracerebral haemorrhage. Cochrane Database Syst Rev. 2008;8(4):CD000200.

79. Barrett RJ, Hussain R, Coplin WM, et al. Frameless stereotactic aspiration and thrombolysis of spontaneous intracerebral hemorrhage. $\mathrm{Neu}$ rocrit Care. 2005;3:237-245.

80. Naff N, Williams MA, Keyl PM, et al. Low-dose recombinant tissue-type plasminogen activator enhances clot resolution in brain hemorrhage: the intraventricular hemorrhage thrombolysis trial. Stroke. 2011;42:3009-3016.

81. Vespa P, McArthur D, Miller C, et al. Frameless stereotactic aspiration and thrombolysis of deep intracerebral hemorrhage is associated with reduction of hemorrhage volume and neurological improvement. Neurocrit Care. 2005;2:274-281.

82. Zhou X, Chen J, Li Q, et al. Minimally invasive surgery for spontaneous supratentorial intracerebral hemorrhage: a meta-analysis of randomized controlled trials. Stroke. 2012;43:2923-2930.

83. Auer LM, Deinsberger W, Niederkorn K, et al. 
Endoscopic surgery versus medical treatment for spontaneous intracerebral hematoma: a randomized study. J Neurosurg. 1989;70(4):530535.

84. Teernstra OP, Evers SM, Lodder J, et al. Stereotactic treatment of intracerebral hematoma by means of a plasminogen activator: a multicenter randomized controlled trial (SICHPA). Stroke. 2003;34:968-974.

85. Newell DW, Shah MM, Wilcox R, et al. Minimally invasive evacuation of spontaneous intracerebral hemorrhage using sonothrombolysis. $J$ Neurosurg. 2011;115(3):592-601.

86. Cho DY, Chen CC, Chang CS, et al. Endoscopic surgery for spontaneous basal ganglia hemorrhage: comparing endoscopic surgery, stereotactic aspiration, and craniotomy in noncomatose patients. Surg Neurol. 2006;65:547556.

87. Marquardt G, Wolff R, Sager A, et al. Subacute stereotactic aspiration of haematomas within the basal ganglia reduces occurrence of com- plications in the course of haemorrhagic stroke in non-comatose patients. Cerebrovasc Dis. 2003;15:252-257.

88. Hanley D, Lane K, Broaddus WC, et al. Misti Trial: 365-day Results Demonstrate Improved Outcomes and Cost Benefit, in International Stroke Conference. Honolulu, Hawaii, 2013.

89. Mould WA, Carhuapoma JR, Muschelli J, et al. Minimally invasive surgery plus recombinant tissue-type plasminogen activator for intracerebral hemorrhage evacuation decreases perihematomal edema. Stroke. 2013;44(3):627-634.

90. Diringer MN, Edwards DF. Admission to a neurologic/neurosurgical intensive care unit is associated with reduced mortality rate after intracerebral hemorrhage. Crit Care Med. 2001;29:635-640.

91. Andrews CM, Jauch EC, Hemphill JC 3rd, et al. Emergency neurological life support: intracerebral hemorrhage. Neurocrit Care. 2012;17 Suppl 1:S37-46. 
Additional Reading

Barrett YC, Wang Z, Frost C, et al. Clinical laboratory measurement of direct factor Xa inhibitors: anti-Xa assay is preferable to prothrombin time assay. Thromb Haemost. 2010;104(6):1263-1271.

Bebulin VH (coagulation factor ix human) kit. Package insert. Baxter International, Inc., Amsterdam, Netherlands. 9/06.

Becker RC, Yang H, Barrett Y, et al. Chromogenic laboratory assays to measure the factor Xa-inhibiting properties of apixaban - an oral, direct and selective factor Xa inhibitor. J Thromb Thrombolysis. 2011;32(2):183-187.

Camm AJ, Lip GY, De Caterina R, et al. 2012 focused update of the ESC Guidelines for the management of atrial fibrillation: an update of the 2010 ESC Guidelines for the management of atrial fibrillation. Developed with the special contribution of the European Heart Rhythm Association. Eur Heart J. 2012;33(21):2719-2747.

ClinicalTrials.gov. http://clinicaltrials.gov/ct2/show/ NCT00708435. Accessed 4/9/13.

CSL Behring. www.cslbehring.com/s1/cs/enco/ 1151517263302/news/1255928833642/prdetail.htm. Accessed 4/22/13.

Da Silva MS, Sobel M. Anticoagulants: to bleed or not to bleed, that is the question. Semin Vasc Surg. 2002;15(4):256-267.

DiMarco JP, Flaker G, Waldo AL, et al; AFFIRM Investigators. Factors affecting bleeding risk during anticoagulant therapy in patients with atrial fibrillation: observations from the Atrial Fibrillation Followup Investigation of Rhythm Management (AFFIRM) study. Am Heart J. 2005;149(4):650-656.

Eriksson BI, Quinlan DJ, Weitz JI. Comparative pharmacodynamics and pharmacokinetics of oral direct thrombin and factor xa inhibitors in development. Clin Pharmacokinet. 2009;48(1):1-22.
Gage BF, Yan Y, Milligan PE, et al. Clinical classification schemes for predicting hemorrhage: results from the National Registry of Atrial Fibrillation (NRAF). Am Heart J. 2006;151(3):713-719.

Gage BF, Birman-Deych E, Kerzner R, et al. Incidence of intracranial hemorrhage in patients with atrial fibrillation who are prone to fall. Am J Med. 2005;118(6):612-617.

Lindhoff-Last E, Samama MM, Ortel TL, et al. Assays for measuring rivaroxaban: their suitability and limitations. Ther Drug Monit. 2010;32(6):673-679.

Orlando Regional Medical Center. www.surgicalcriticalcare.net/Guidelines/Warfarin\%20Reversal\%20 Guideline\%202012.pdf. Accessed 4/15/13.

Pisters R, Lane DA, Nieuwlaat R, et al. A novel userfriendly score (HAS-BLED) to assess 1-year risk of major bleeding in patients with atrial fibrillation: the Euro Heart Survey. Chest. 2010;138(5):1093-1100.

Profilnine SD (factor ix complex). Package insert. Grifols Biologicals, Barcelona, Spain. 8/11.

Schulman S, Crowther MA. How I treat with anticoagulants in 2012: new and old anticoagulants, and when and how to switch. Blood. 2012;119(13):30163023.

Singer DE, Chang Y, Fang MC, et al. The net clinical benefit of warfarin anticoagulation in atrial fibrillation. Ann Intern Med. 2009;151(5):297-305.

Steffel J, Braunwald E. Novel oral anticoagulants: focus on stroke prevention and treatment of venous thrombo-embolism. Eur Heart J. 2011;32(16):19681976.

van Ryn J, Stangier J, Haertter S, et al. Dabigatran etexilate-a novel, reversible, oral direct thrombin inhibitor: interpretation of coagulation assays and reversal of anticoagulant activity. Thromb Haemost. 2010;103(6):1116-1127.

Weitz JI, Quinlan DJ, Eikelboom JW. Periprocedural management and approach to bleeding in patients taking dabigatran. Circulation. 2012;126(20):2428-2432. 


\section{POSTTEST, EVALUATION, and REQUEST FOR CREDIT FORM}

\section{Race Against the Clock: \\ Overcoming Challenges in the Management of Anticoaglant-Associated Intracerebral Hemorrhage}

To receive a CME certificate of participation, participants must:

(1) Read the entire publication (including the CME information).

(2) Earn a posttest score of at least $70 \%$ and complete an evaluation form.

(3) Either register or log in at www.paradigmmc.com/JNSpub and complete and submit the online posttest and evaluation (a certificate of participation will be available for download/printing immediately following successful completion of the posttest and evaluation) OR complete the form below and mail or fax to Paradigm Medical Communications, LLC, 523 Route 303, Orangeburg, NY 10962; fax (845) 398-5108 (an email with a link to your certificate will be issued 1 to 2 weeks after receipt of completed form).

POSTTEST (please indicate the most appropriate answer)

1. AAICH is on the rise because the population is aging and because of the increased usage of warfarin and NOACs. Use of warfarin and NOACs is associated with an increased risk of ICH. Which of the following statements about AAICH is false:

- AAICH accounts for $8-15 \%$ of all ICH

- Patients with ICH taking anticoagulation therapy with warfarin have a higher risk of death at 30 days

- AAICH is associated with a $50 \%$ mortality rate

- Patients presenting with $\mathrm{ICH}$ and who are on anticoagulation therapy have a reduced risk of hematoma expansion

2. Which of the following is a correct statement about warfarin-associated ICH?

- Most occur within the conventional therapeutic INR range (2-3.5)

- Most occur just above the conventional therapeutic INR range (3.5-4.0)

- Most occur well above the conventional therapeutic INR range $(>4.0)$

3. Which of the following repletion options for AAICH requires blood typing?

- IV vitamin $\mathrm{K}$

- Fresh frozen plasma (FFP)

- Recombinant factor VIIa ( $\mathrm{rFVIIa)}$

- Prothrombin complex concentrates (PCCs)
4. Which of the following statements is false according to current AHA and ASA published guidelines for the management of spontaneous ICH?

- Maintain a mean arterial pressure of less than $130 \mathrm{mmHg}$

- Maintain a cerebral perfusion pressure of at least $60 \mathrm{mmHg}$

- A brain CT scan should be performed

- Anticoagulation should be restarted as soon as the patient is stabilized

5. In order to induce rapid correction of warfarin-associated coagulopathy, existing guidelines endorse the administration of IV vitamin $\mathrm{K}$ in combination with which of the following?

O FFP and 3-factor PCC

○ Dabigatran

- Aspirin

- rFVIla

6. When administering 3-factor PCC to reverse warfarinassociated ICH, which of the following would NOT be on your list of considerations?

- Viral transmission

- Thrombosis

- Inadequate INR correction

- Variable cofactor content 


\section{Evaluation}

\section{Race Against the Clock:}

\section{Overcoming Challenges in the Management of Anticoagulant-Associated Intracerebral Hemorrhage}

\begin{tabular}{|c|c|c|c|c|c|c|c|c|c|c|}
\hline \multicolumn{5}{|c|}{$\begin{array}{l}\text { Prior to participating in this activity, how } \\
\text { confident were you in your ability to: }\end{array}$} & \multirow{2}{*}{$\begin{array}{c}\text { Please indicate your response using the following scale: } \\
\text { 1-Not at All Confident; 3-Confident; 5-Very Confident } \\
\text { Use knowledge of guidelines for the management of AAICH } \\
\text { promulgated by the AHA/ASA and the ACCP }\end{array}$} & \multicolumn{5}{|c|}{$\begin{array}{l}\text { After participating in this activity, how } \\
\text { confident are you now in your ability to: }\end{array}$} \\
\hline $\begin{array}{l}1 \\
0\end{array}$ & $\begin{array}{l}2 \\
0\end{array}$ & $\begin{array}{l}3 \\
0\end{array}$ & $\begin{array}{l}4 \\
0\end{array}$ & $\begin{array}{l}5 \\
\bigcirc\end{array}$ & & $\begin{array}{l}1 \\
0\end{array}$ & $\begin{array}{l}2 \\
\bigcirc\end{array}$ & $\begin{array}{l}3 \\
0\end{array}$ & $\begin{array}{l}4 \\
0\end{array}$ & $\begin{array}{l}5 \\
0\end{array}$ \\
\hline 1 & $\begin{array}{l}2 \\
0\end{array}$ & 3 & $\begin{array}{l}4 \\
0\end{array}$ & 5 & $\begin{array}{l}\text { Advance evidence-based and protocol-driven treatment } \\
\text { strategies for AAICH within your own practice setting }\end{array}$ & 1 & $\begin{array}{l}2 \\
\bigcirc\end{array}$ & 3 & 4 & 5 \\
\hline 1 & 2 & 3 & $\begin{array}{l}4 \\
0\end{array}$ & 5 & $\begin{array}{l}\text { Select appropriate anticoagulation reversal strategies in the } \\
\text { management of patients with } \mathrm{AAICH}\end{array}$ & 1 & 2 & 3 & $\begin{array}{l}4 \\
0\end{array}$ & $\begin{array}{l}5 \\
\bigcirc\end{array}$ \\
\hline
\end{tabular}

Please indicate your response to questions 1-5 using this scale: 1-Strongly Disagree 2-Disagree 3-Neutral 4-Agree 5-Strongly Agree

1. The following objectives of the activity were achieved:

$123 \quad 3 \quad 45$

- Appropriately apply evidence-based guidelines and strategies to the management of patients with warfarin-associated ICH.

$\begin{array}{lllll}0 & 0 & 0 & 0 & 0\end{array}$

- Recognize the barriers to successful management of patients with ICH in the context of anticoagulation-associated coagulopathy.

$\begin{array}{lllll}0 & 0 & 0 & 0 & 0\end{array}$

- $\quad$ Based on the risk/benefit analysis of reversal agents, select appropriate therapies for the treatment of patients with AAICH.

$\begin{array}{llllll}0 & 0 & 0 & 0 & 0\end{array}$

2. The following authors delivered content in a concise, unbiased manner:

- $\quad$ Peter D. Le Roux, MD, FACS

- $\quad$ Charles V. Pollack, Jr, MA, MD, FACEP

3. The activity was free of commercial bias (If disagree or strongly disagree, please describe in \#11).

4. The educational strategy used in this activity was appropriate.

$\begin{array}{lllll}0 & 0 & 0 & 0 & 0\end{array}$

5. The content of the activity was relevant to my practice.

0

0

$\begin{array}{lllll}0 & 0 & 0 & 0 & 0\end{array}$

6. As a result of your participation in this activity, what will you do differently in the care of your patients?

7. What barriers to applying what you learned do you anticipate?

8. What challenges are you faced with when managing patients with AAICH?

9. What other issue(s) would you like to see addressed in future CME activities?

10. Which activity format do you prefer? (check all that apply) O Live national meetings O Live local meetings $\mathrm{O}$ Live Grand Rounds O Print O Online print O E-mobile activities O On-demand webinars O Other (specify):

11. Other comments or suggestions:

REQUEST FOR CREDIT (please print clearly)

I certify that I have completed this educational activity and claim credit hours (maximum of 1.5 ).

Name: Signature:

Company/Organization:

Degree(s): Specialty: NPI\#:

Address City: State: ZIP:

Phone: Fax: Email: 